\title{
The Brewer-Dobson Circulation in a Changing Climate: Impact of the Model Configuration
}

\author{
FELIX BUNZEL \\ Max Planck Institute for Meteorology, and International Max Planck Research School on Earth System \\ Modelling, Hamburg, Germany \\ HAUKE SCHMIDT \\ Max Planck Institute for Meteorology, Hamburg, Germany
}

(Manuscript received 30 July 2012, in final form 14 November 2012)

\begin{abstract}
Most climate models simulate a strengthening of the Brewer-Dobson circulation (BDC) under a changing climate. However, the magnitude of the trend as well as the underlying mechanisms varies significantly among the models. In this work the impact of both vertical resolution and vertical extent of a model on the simulated BDC change is investigated by analyzing sensitivity simulations performed with the general circulation model ECHAM6 in three different model configurations for three different climate states. Tropical upwelling velocities and age of stratospheric air are used as measures for the strength of the BDC. Both consistently show a BDC strengthening from the preindustrial to the future climate state for all configurations of the model. However, the amplitude and origin of this change vary between the different setups. Analyses of the tropical upward mass flux indicate that in the model with a lid at $10 \mathrm{hPa}$ the BDC strengthening at $70 \mathrm{hPa}$ is primarily produced by resolved wave drag, while in the model with a higher lid $(0.01 \mathrm{hPa})$ the parameterized wave drag yields the main contribution to the BDC increase. This implies that consistent changes in the BDC originate from different causes when the stratosphere is not sufficiently resolved in a model. Furthermore, the effect of enhancing the horizontal diffusion in the upper model layers to avoid resolved wave reflection at the model lid is quantified, and a possible link to the different behavior of the low-top model with regard to the origin of the BDC change is identified.
\end{abstract}

\section{Introduction}

Above the tropopause, breaking and dissipation of different types of atmospheric waves induce an atmospheric meridional overturning circulation, which in the stratosphere is often referred to as the Brewer-Dobson circulation (BDC). Several recent simulations performed with different middle-atmosphere models predict a strengthening of this circulation under a changing climate induced by increasing greenhouse gas (GHG) concentrations (e.g., Butchart et al. 2006; Li et al. 2008; Garcia and Randel 2008; Karpechko and Manzini 2012). Observational datasets do not support this finding. However, because of large uncertainties in the measurements and the lack of long observational time series, model results cannot be disproved by observational data (Engel et al. 2009).

Corresponding author address: Felix Bunzel, Max Planck Institute for Meteorology, Bundesstr. 53, 20146 Hamburg, Germany. E-mail: felix.bunzel@zmaw.de
Changes in the strength and pattern of the BDC are expected to modify the stratospheric composition (Butchart and Scaife 2001). Particularly, a modification in transport of ozone itself and ozone-depleting substances, such as chlorofluorocarbons (CFCs), would alter the stratospheric ozone distribution. For example, Jiang et al. (2007) found that a GHG-induced BDC strengthening leads to a decrease in ozone concentrations in the tropics and an increase in ozone concentrations in the high latitudes. A redistribution of stratospheric ozone would not only yield feedback mechanisms for stratospheric dynamics but also affect the penetration of UV radiation into the troposphere (e.g., Rind et al. 1990; Hegglin and Shepherd 2009). Thus, in order to improve the accuracy of model simulations with regard to the future evolution of climate and chemical composition of the atmosphere, a good estimation of the change in BDC strength is important.

In comprehensive middle-atmosphere models, there are generally two ways to obtain a measure of the BDC 
strength. Either the tropical upward mass flux is evaluated from the residual mean meridional circulation, as formulated by Andrews et al. (1987) in the transformed Eulerian mean (TEM) framework, or the mean age of stratospheric air (Hall and Plumb 1994) is extracted from the model. Austin and Li (2006) showed that a linear relation exists between the tropical upwelling velocity and the age of stratospheric air and that both quantities indicate a future acceleration of the BDC.

Within the Chemistry-Climate Model Validation (CCMVal) activity the BDC strength and its trend were analyzed in many different chemistry-climate models (CCMs) and their underlying general circulation models (GCMs). In the second phase of the CCMVal activity (CCMVal-2), the multimodel average showed that resolved waves account for roughly $70 \%$ of the driving of the annual-mean total upward mass flux at $70 \mathrm{hPa}$, while the remaining $30 \%$ are largely due to orographic and nonorographic gravity waves (Butchart et al. 2011). However, a wide spread between the models in the contributions from different types of wave drag was obtained. The CCMVal-1 models showed that also the origin of the trend in the 70-hPa upward mass flux from the troposphere to the stratosphere varies among CCMs (Butchart et al. 2010). In some CCMs the resolved wave drag yields the major contribution, and in other models the contribution of unresolved wave drag is predominant. While in the multimodel mean of the GCM Reality Intercomparison Project for Separation of Pixels Using Aggregated Rating over Canada (SPARC) (GRIPS; Pawson et al. 2000) resolved waves were found to cause $60 \%$ of the trend at $70 \mathrm{hPa}$ (Butchart et al. 2006), their contribution is roughly $40 \%$ in the multimodel mean of the CCMVal-1 models (Butchart et al. 2010). As in most of the models involved in these studies different representations of the stratosphere are used, particularly with regard to the vertical resolution and the vertical model extent, a dependency of the obtained results on the configuration of a model cannot be ruled out. The parameterization scheme applied in a model to account for the unresolved orographic and nonorographic gravity wave drag is also a possible source for the unequal importance of the parameterized wave drag contribution among the models.

It was argued by Garcia and Randel (2008) that the mechanism responsible for the strengthening of the BDC originates from the GHG-induced increase in tropospheric and decrease in stratospheric temperatures. Via thermal wind balance the increase of the meridional temperature gradient strengthens the upper flank of the subtropical jets and, thus, the conditions for wave propagation are modified. Particularly, McLandress and Shepherd (2009) found that the dissipation level of orographic gravity waves is shifted upward in simulations of the twenty-first century performed with the Canadian Middle Atmosphere Model (CMAM). Also, the critical layers for resolved wave dissipation on the equatorward side of the jets underlie an upward shift, causing more resolved wave activity to penetrate into the subtropical lower stratosphere (Shepherd and McLandress 2011).

In this work we analyze the simulated change in both the BDC and its driving forces in the state-of-the-art ECHAM6 GCM, and perform for the first time a systematic investigation of the impact of the model configuration by using different vertical resolutions and different vertical extents of the same model. A low-top configuration with a lid at $10 \mathrm{hPa}$ is applied, which represents an older model generation and was used in phase 3 of the Coupled Model Intercomparison Project (CMIP3; Roeckner et al. 2006). On the other hand, two high-top configurations with a lid at $0.01 \mathrm{hPa}$ and different vertical resolutions were applied, which are used in coupled atmosphere-ocean GCM simulations carried out for CMIP5. A comparison of the results of the two hightop configurations allows us to quantify the impact of an internally generated quasi-biennial oscillation (QBO).

Age of stratospheric air and the tropical upwelling velocity are used as measures to assess the BDC strength. To disentangle the contribution of different wave types to the BDC and its change over time, the downward-control principle (Haynes et al. 1991) is applied. Thus, the impact of unresolved and resolved waves on the BDC pattern and strength can be evaluated.

In section 2 a detailed description of the applied methods to derive measures for the BDC strength, circulation pattern, and the attribution of the effects to different types of wave drag is given. Simulation strategy and model description are provided in section 3, while the results are presented in section 4 . Section 5 contains a summary of the results as well as some concluding remarks.

\section{Methods to measure the BDC}

Passive tracers in a GCM can be used to obtain the mean age and the associated age spectrum of a stratospheric air parcel (Hall and Plumb 1994). In combination with the residual mean meridional circulation as formulated by Andrews et al. (1987), which is a good approximation of the BDC, a useful diagnostic of stratospheric transport processes is obtained. By applying the downward-control principle (Haynes et al. 1991), the impact of different types of wave drag on both the circulation pattern of the BDC and the tropospherestratosphere mass exchange can be assessed. 


\section{a. The age of air}

Using the tracer interface of the ECHAM6 GCM, we implemented an approach to derive the mean age of a stratospheric air parcel as well as its associated age spectrum. Following the work of Hall and Plumb (1994), passive tracers were injected during a model simulation, which are transported by the winds and interacting with neither chemistry nor radiation.

To obtain the mean age of an air parcel, a tracer with linearly increasing concentrations is injected into the lowermost model level at every grid point between $-5^{\circ}$ and $+5^{\circ}$ latitude. The tracer species is then transported by the winds on various BDC pathways with different transit times before it is recirculated. After an initialization time of about $20 \mathrm{yr}$, to a good approximation all possible transit times for air parcels are covered, and the tracer circulation can be considered to be in equilibrium.

If the mixing ratio of a conserved tracer, $n=n(P, t)$, is prescribed at the injection point $P_{0}$, and $n\left(P_{0}, t\right)=0$ for $t<0$, then the tracer mixing ratio at some other point $P$ can be derived by

$$
n(P, t)=\int_{0}^{t} n\left(P_{0}, t-t^{\prime}\right) G\left(P, P_{0}, t^{\prime}\right) d t^{\prime},
$$

where the Green's function $G\left(P, P_{0}, t^{\prime}\right)$ represents the distribution of transit times from $P_{0}$ to $P$-that is, the age spectrum (Hall and Plumb 1994). The mean age $\Gamma$ of an air parcel can then be defined as the average of the component transit times:

$$
\Gamma\left(P, P_{0}\right)=\int_{0}^{\infty} t G\left(P, P_{0}, t\right) d t .
$$

Using a linearly increasing passive tracer, all information on single air parcels is lost, which is due to irreversible mixing processes. The age spectrum $G\left(P, P_{0}, t^{\prime}\right)$ is unknown. If one would neglect the mixing of air parcels in the stratosphere, the Green's function could be replaced by Dirac's delta distribution, $G\left(P, P_{0}, t^{\prime}\right)=\delta\left(t-t_{0}\right)$, where $t_{0}$ would represent the transit time of an air parcel from $P_{0}$ to $P$ (Hall and Plumb 1994). Applying this to Eq. (2) a measure for the age of air $\Gamma$ in the absence of mixing processes could simply be obtained by the lag time $t_{0}$ of tracer concentrations from $P_{0}$ to $P$. Hall and Plumb (1994) showed that in the more general case, when stratospheric mixing processes are considered and, thus, the age spectrum of an air parcel has a finite width, this result also holds in the long time limit for a linearly increasing passive tracer.

Following Hall and Plumb (1994) we derive the age spectrum of an air parcel by injecting a tracer pulse into the model. For a single time step the mixing ratio of a passive tracer is set to 1 at every grid point between $-5^{\circ}$ and $+5^{\circ}$ latitude in the lowermost model level. Before and after this time step the mixing ratio is forced to 0 at the same grid points. In this way the tracer concentration in the injection grid points simulates a "scaled" Dirac's delta distribution. Applying all this to Eq. (1) shows that the age spectrum at some grid point $P$ can be obtained by the tracer concentration in that grid point. A certain amount of this tracer pulse escapes the injection grid points between the injection and the following time step. To normalize the age spectrum it is divided by the total abundance of the tracer species left in the model at the time step, at which the age spectrum is read out. To account for seasonal differences in transport, one tracer pulse is injected on 1 January and another one on 1 July. Every $12 \mathrm{yr}$ tracer concentrations are being reset and a new pulse is injected. By building the mean age spectrum of several tracer pulses, effects originating from possible special atmospheric states can be reduced.

\section{b. The residual mean meridional circulation}

The zonal momentum equation formulated according to Andrews et al. (1987) in the TEM framework, using the log-pressure vertical coordinate $z$, is

$$
\begin{aligned}
\frac{\partial \bar{u}}{\partial t} & +\bar{v}^{*}\left[\frac{1}{a \cos \phi} \frac{\partial}{\partial \phi}(\bar{u} \cos \phi-2 \Omega \sin \phi)\right]+\bar{w}^{*} \frac{\partial \bar{u}}{\partial z} \\
& =\frac{1}{\rho_{0} a \cos \phi} \nabla \cdot \mathbf{F}+\overline{X_{\mathrm{OGWD}}}+\overline{X_{\mathrm{NGWD}}}+\bar{X} .
\end{aligned}
$$

Here the residual mean meridional circulation is represented by the velocity components $\bar{v}^{*}$ and $\bar{w}^{*}$, which describe the transport of air parcels in the meridional slice taking into account eddy effects. These components can also be used to define a "directly calculated" streamfunction $\psi$ (e.g., Haynes et al. 1991). The zonalmean zonal wind is represented by $\bar{u}, a$ and $\Omega$ describe radius and rotation rate of Earth, respectively, $\phi$ is the latitude coordinate, and $t$ is time. The terms on the righthand side of Eq. (3) can be considered as the drivers of the residual circulation. This is particularly true in the steady state, where $\bar{u}$ does not change over time. The first term on the right-hand side of Eq. (3) comprises the Eliassen-Palm flux divergence (EPFD) and represents the contribution of the resolved wave drag to the residual circulation (Eliassen and Palm 1960), while $\overline{X_{\mathrm{OGWD}}}$ and $\overline{X_{\mathrm{NGWD}}}$ respectively contain the contributions of parameterized orographic (OGWD) and nonorographic (NGWD) gravity wave drags. The latter two comprise small-scale processes, which are not resolved in the applied model configuration. The term $\bar{X}$ accounts for the resolved wave momentum, which is damped into the upper model layers in order to avoid wave reflection 
at the upper boundary of the model (Roeckner et al. 2003). In the low-top configuration (model lid at $10 \mathrm{hPa}$ ) of the ECHAM6 GCM this term becomes significantly large, as the momentum carried particularly by largescale planetary waves is not negligible here.

By using the downward-control principle (Haynes et al. 1991), according to which the meridional circulation at each level is controlled only by the forces acting above it, separate streamfunctions for resolved and parameterized wave drag contributions can be evaluated. The resulting expression for the streamfunction derived under the downward-control assumption writes

$$
\psi(\phi, z)=\int_{z}^{\infty}\left\{\frac{\rho_{0} a^{2} \bar{D} \cos ^{2} \phi}{\bar{m}_{\phi}}\right\}_{\phi=\phi\left(z^{\prime}\right)} d z^{\prime},
$$

where $\bar{D}$ represents the respective drag term, to be evaluated (Haynes et al. 1991). Above the model lid, the drag terms associated with different wave types are treated differently in the ECHAM6 GCM (see section 3). To simplify the calculation of the latitude derivative of the zonal-mean angular momentum $\bar{m}_{\phi}$ along a contour of constant $\bar{m}$, the zonal-mean angular momentum is often assumed to be constant with height at extratropical latitudes. However, to improve accuracy, we calculate $\bar{m}_{\phi}$ at every latitude in the lowermost model level and follow lines of constant angular momentum by linear interpolation of $\bar{m}_{\phi}$. A comparison to the more simplified approach showed slight deviations in the subtropics and negligible differences at higher latitudes.

The mass streamfunction $\psi_{m}$ we obtain by

$$
\psi_{m}(\phi, z)=2 \pi a \psi(\phi, z)
$$

Following McLandress and Shepherd (2009) and Okamoto et al. (2011), we derive the net upward mass flux through a level $z_{l}$ by the difference in mass streamfunction at the turnaround latitudes:

$$
M_{z_{l}}=\psi_{m}\left(\phi_{t}^{\mathrm{NH}}, z_{l}\right)-\psi_{m}\left(\phi_{t}^{\mathrm{SH}}, z_{l}\right) .
$$

The turnaround latitudes $\phi_{t}^{\mathrm{NH}}$ and $\phi_{t}^{\mathrm{SH}}$ on the Northern $(\mathrm{NH})$ and Southern (SH) Hemispheres, respectively, are defined as the latitudes where $\bar{w}^{*}$ changes sign.

\section{Simulation strategy and model description}

The ECHAM6 GCM (Stevens et al. 2013) was used in the time-slice mode to perform sensitivity simulations under stationary boundary conditions for preindustrial (1860), present-day (1990), and future (2050) climate states. For each time slice $50 \mathrm{yr}$ were simulated after a spinup time of $5 \mathrm{yr}$. Associated input data for $\mathrm{GHG}$ concentrations [including also chlorofluorocarbons (CFCs)], sea surface temperatures (SSTs), sea ice coverage (SIC), ozone distribution, and aerosols were applied to simulate the different climate states. For the future time slice, generally, the representative concentration pathway mitigation scenario RCP4.5 (van Vuuren et al. 2011) was the reference. Both SST and SIC input data were taken from the output of coupled atmosphere-ocean GCM simulations performed with ECHAM5 (Roeckner et al. 2003) coupled to the Max Planck Institute Ocean Model (MPI-OM; Marsland 2003), which were carried out for CMIP3. The Special Report on Emissions Scenarios (SRES) A1B scenario (Nakicenovic and Swart 2000) was used here to compile input data for SST and SIC fields, as the associated CMIP5 simulations were not completed by the start of the experiments performed in the context of this work.

To address the impact of the vertical resolution and the vertical extent of the model, each time-slice simulation was performed in three different model configurations. The high-top model version extending up to $0.01 \mathrm{hPa}$ was used in a low-resolution (47 levels; L47) and in a high-resolution mode (95 levels; L95). Additionally, all simulations were also performed with the low-top version of the model using 31 levels (L31) and extending up to $10 \mathrm{hPa}$. Up to the tropopause the levels in the L31 configuration are the same as in the L47 model. The QBO is simulated only in the L95 configuration, where it is internally generated (Krismer et al. 2012, manuscript submitted to J. Adv. Model. Earth Syst.). In our simulations the QBO period is roughly 27 months.

In all simulations the horizontal resolution is T63 $\left(1.9^{\circ} \times 1.9^{\circ}\right)$. Roeckner et al. $(2006)$ studied the sensitivity of the simulated climate to both horizontal and vertical resolution in the ECHAM5 low-top GCM. The performance of the middle-atmosphere version of the same GCM was analyzed by Manzini et al. (2006). To account for effects of unresolved atmospheric waves, ECHAM6 uses a gravity wave parameterization scheme following Lott and Miller (1997). This scheme captures the impact of gravity waves originating from subgridscale orography. In the L47 and L95 configurations of the model, effects originating from nonorographic gravity waves are also accounted for. A parameterization scheme after Hines (1997) is used. The impact of varying the source spectrum of this gravity wave parameterization scheme was analyzed by Manzini and McFarlane (1998) in the middle-atmosphere version of ECHAM4, the MAECHAM4 GCM. More information about the gravity wave parameterization scheme used in ECHAM6, its differences to ECHAM5, as well as the performance 
(a) T diff. [K], fut.-preind., L95, DJF

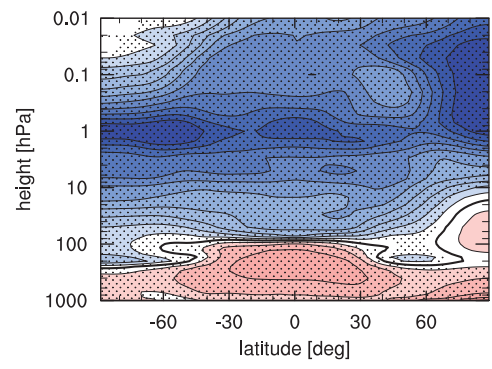

(d) u diff. [m/s], fut.-pi., L95, DJF

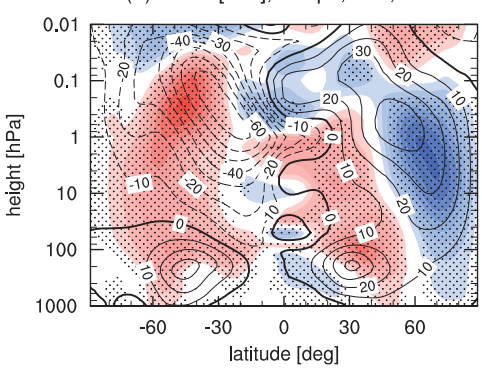

(b) T diff. [K], fut.-preind., L47-L95, DJF

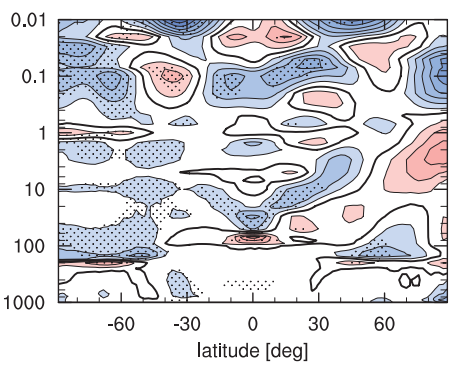

(e) u diff. [m/s], fut.-pi., L47-L95, DJF

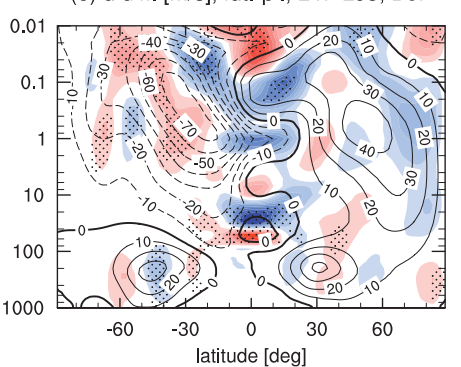

(c) T diff. [K], fut.-preind., L31-L95, DJF

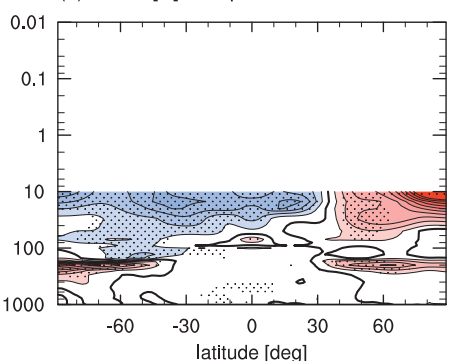

(f) u diff. [m/s], fut.-pi., L31-L95, DJF

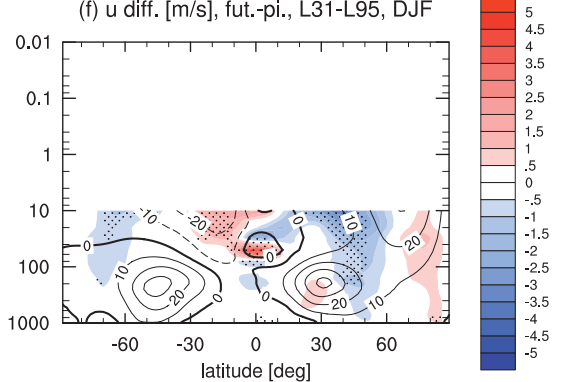

FIG. 1. The difference in (a)-(c) annual-mean temperature and (d)-(f) zonal-mean zonal wind between preindustrial and future time slices, as simulated in (a),(d) the L95 configuration, is shown. The impact of the model configuration is reflected by subtracting these differences from the associated differences in (b),(e) the L47 and (c),(f) the L31 configurations of the model. Black contour lines in (d)-(f) show the preindustrial zonal-mean zonal wind field in the L95 configuration. Dotted areas indicate significance at the $95 \%$ confidence level after a $t$ test. Note that the color contours of the plots comparing different model configurations use 4 (2) times lower values for the temperature (zonal wind) field than the contours of the L95 configuration plot.

of ECHAM6 with regard to the middle atmosphere can be found in Schmidt et al. (2013).

To avoid the reflection of resolved waves at the model lid, in all model configurations the momentum carried by the resolved waves is damped into the uppermost five model layers (for $\mathrm{T} 63$, from $90 \mathrm{hPa}$ upward) by enhancing the horizontal diffusion (Roeckner et al. 2003). While the momentum carried by nonorographic gravity waves is damped into the upper layers of the high-top model by setting the momentum flux to zero in the uppermost half-level, the orographic gravity wave momentum flux is not conserved.

In all simulations the mean age of stratospheric air was derived via a passive tracer with linearly increasing concentrations, which was initialized at the surface. Following Manzini and Feichter (1999), who calculated the age of air for MAECHAM4, the 110-hPa level at the equator is used as the reference point for the age. In our simulations we additionally derive the age spectrum via tracer pulses. As in each time-slice experiment $50 \mathrm{yr}$ were simulated, and four summer and four winter tracer pulses were injected to determine the age spectrum of a stratospheric air parcel (see section 2a). Thus, the resulting age spectrum is built from eight pulsed tracer injections.

\section{Results of time-slice simulations}

In this section, the results obtained from the time-slice simulations described in the previous section are evaluated. In all model configurations we find a GHG induced increase in tropospheric temperature and a decrease in stratospheric temperature from the preindustrial to the future climate state [see Figs. 1a-c for the DecemberFebruary (DJF) season]. The temperature change in NH winter is significant at the $95 \%$ confidence level (after a $t$ test) everywhere except for the $\mathrm{NH}$ polar lower-tomiddle stratosphere. This was also reported by previous studies (e.g., Butchart et al. 2000), who attributed the distinct behavior of the polar lower-to-middle stratosphere to significant interannual variability resulting from planetary wave forcing from the troposphere. In our simulations the slight temperature increase in this region, which is not significant at the $95 \%$ confidence level, could be related to an increasing number of sudden stratospheric warming (SSW) events, as the SSW frequency is found to increase in the future climate state by roughly $50 \%$ in both high-top model configurations.

Via thermal wind balance the change in the meridional temperature gradient, which is present in all model configurations (see Fig. 1a for the L95 configuration), 
TABLE 1. The seasonal 70-hPa upward mass flux $\left(\times 10^{8} \mathrm{~kg} \mathrm{~s}^{-1}\right)$ in the present-day (1990) climate state, derived from time-slice simulations in (second column) the L31, (third column) L47, and (fourth column) the L95 configurations of the model, is presented. Numbers in parentheses are one standard deviation. Seasons are DJF, MarchMay (MAM), June-August (JJA), and September-November (SON).

\begin{tabular}{llll}
\hline Season & $\begin{array}{c}\text { T63L31 } \\
\text { (low top) }\end{array}$ & $\begin{array}{c}\text { T63L47 } \\
\text { (high top) }\end{array}$ & $\begin{array}{c}\text { T63L95 } \\
\text { (high top) }\end{array}$ \\
\hline DJF & $74.2( \pm 3.0)$ & $99.8( \pm 3.8)$ & $95.8( \pm 3.8)$ \\
MAM & $60.9( \pm 1.8)$ & $77.4( \pm 2.4)$ & $75.4( \pm 2.7)$ \\
JJA & $49.9( \pm 2.3)$ & $67.1( \pm 3.0)$ & $65.4( \pm 3.2)$ \\
SON & $65.6( \pm 2.9)$ & $82.4( \pm 4.5)$ & $80.5( \pm 3.5)$ \\
Annual & 59.9 & 76.4 & 74.1 \\
\hline
\end{tabular}

is expected to cause a modification of the zonal-mean zonal wind field. As a response to the latitude dependency of the change in the temperature field, which is prominent especially in the tropopause region, a strengthening of the upper flank of the subtropical jets is simulated in all seasons (see Figs. 1d-f for the DJF season). This strengthening was previously reported by several other studies (e.g., Rind et al. 1998; Sigmond et al. 2004; Lu et al. 2008; McLandress and Shepherd 2009) and is found to be largest in the DJF season in all model configurations. Shepherd and McLandress (2011) argue that the strengthening of the upper flank of the subtropical jets leads to an upward shift of the critical layers for wave dissipation. This would allow more wave activity to penetrate into the subtropical lower stratosphere, inducing a strengthening of the BDC. Garcia and Randel (2008) identified that enhanced wave propagation and dissipation in the subtropical lower stratosphere due to the strengthening of the subtropical jets leads to an acceleration of the BDC.

In the tropics the change in the zonal-mean zonal wind field between preindustrial and future climate states reveals differences in the simulated QBO. As we find that the largest total upward mass fluxes at $70 \mathrm{hPa}$ in $\mathrm{NH}$ winter mostly occur when the QBO is in the easterly phase at $30 \mathrm{hPa}$, differences in the simulated QBO could affect the strength of the tropical upwelling via the secondary meridional circulation (e.g., Plumb and Bell 1982). Plumb and Eluszkiewicz (1999) argued that the QBO modulation of the tropical angular momentum structure could be significant. During the easterly phase of the QBO, this potentially enhances the tropical upwelling (Semeniuk and Shepherd 2001).

By comparing zonal-mean zonal wind and temperature changes in L47 and L95 model configurations (Fig. 1), the combined effect of increasing the vertical resolution and the simulation of the QBO, which is generated only in the L95 configuration, can be evaluated. A typical
TABLE 2. The seasonal increase in $70-\mathrm{hPa}$ upward mass flux $\left(\times 10^{8} \mathrm{~kg} \mathrm{~s}^{-1}\right)$ from the preindustrial (1860) to the future (2050) climate state, derived from time-slice simulations in (second column) the L31, (third column) the L47, and (fourth column) the L95 configurations of the model, is presented. Numbers in parentheses show the relative increase.

\begin{tabular}{lcrr}
\hline \hline Season & $\begin{array}{c}\text { T63L31 } \\
\text { (low top) }\end{array}$ & $\begin{array}{c}\text { T63L47 } \\
\text { (high top) }\end{array}$ & $\begin{array}{c}\text { T63L95 } \\
\text { (high top) }\end{array}$ \\
\hline DJF & $10.1(14.4 \%)$ & $12.7(13.4 \%)$ & $14.9(16.5 \%)$ \\
MAM & $7.7(13.2 \%)$ & $10.3(13.7 \%)$ & $11.7(16.3 \%)$ \\
JJA & $6.1(12.9 \%)$ & $8.4(12.9 \%)$ & $8.8(13.7 \%)$ \\
SON & $6.2(09.9 \%)$ & $7.4(09.3 \%)$ & $8.0(10.3 \%)$ \\
Annual & $7.1(12.7 \%)$ & $9.5(12.9 \%)$ & $10.7(15.1 \%)$ \\
\hline
\end{tabular}

QBO-like pattern is apparent throughout the entire tropical stratosphere. Significant differences in the extratropics in both zonal wind and temperature changes might originate from the secondary meridional circulation, which is induced by the QBO. The meridional gradient in the temperature change is found to be slightly larger in the L47 configuration compared to the L95 configuration of the model, possibly explaining the larger strengthening of the upper jet flank on the $\mathrm{NH}$ in DJF (Fig. 1e). This could lead to an acceleration of the meridional circulation. For the strength of the total upward mass flux, however, a modulation of the QBO might have a stronger effect.

The most significant differences in DJF temperature change in the L31 model compared to the L95 model occur in the uppermost model levels, where the horizontal diffusion is artificially enhanced (see section 3 ). Here the temperature drop from the preindustrial to the future climate state is significantly stronger than in the L95 model except for the northern high latitudes. With regard to the critical layers for wave dissipation, the weaker change in zonal-mean zonal winds in the L31 model implies a weaker BDC response.

Table 1 shows the seasonal total upward mass flux through the $70-\mathrm{hPa}$ pressure surface for the different model configurations. While all models simulate the peak upward mass flux in DJF with a similar magnitude in both high-top configurations, the mass flux is significantly lower (by roughly $25 \%$ ) in the L31 model in all seasons. Changes in the upward mass flux from the preindustrial to the future climate state (see Table 2) reveal an increase in all seasons and model configurations. The L31 model simulates the weakest increase in upward mass flux, which is consistent with the findings of Karpechko and Manzini (2012), who found a stronger response in tropical upwelling under increased GHG concentrations in the ECHAM5 high-top model compared to the lowtop configuration. Since in our simulations both the strongest upward mass flux as well as the highest increase in 
(a) Streamfunction $[\mathrm{kg} / \mathrm{m} / \mathrm{s}]$, L95, DJF

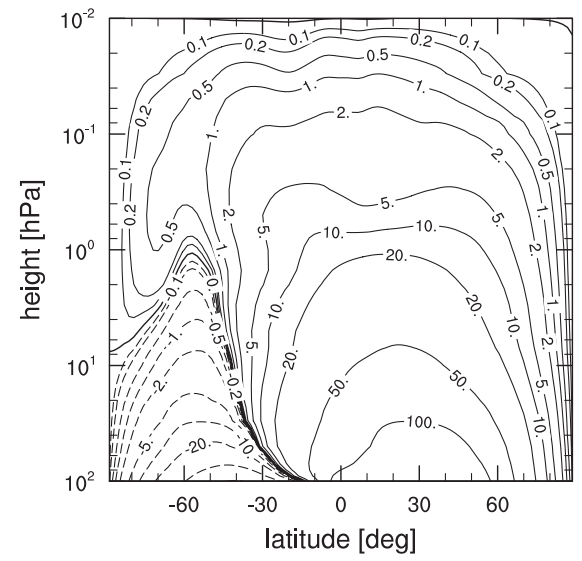

(c) EPFD streamfunction $[\mathrm{kg} / \mathrm{m} / \mathrm{s}]$, DJF (b) DWC streamfunction $[\mathrm{kg} / \mathrm{m} / \mathrm{s}]$, DJF

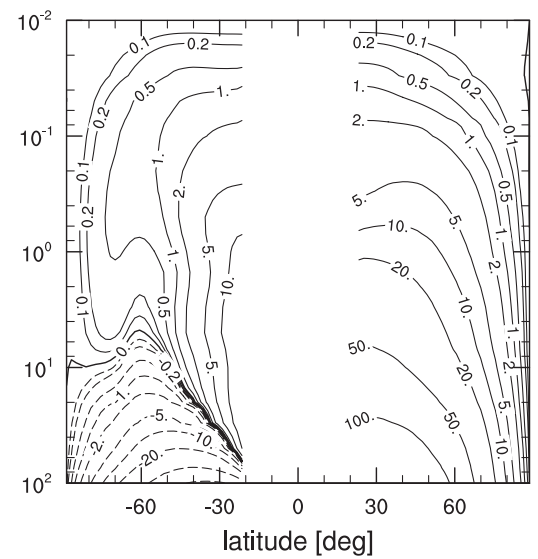

(d) OGWD streamfunction [kg/m/s], DJF (e) NGWD streamfunction [kg/m/s], DJF

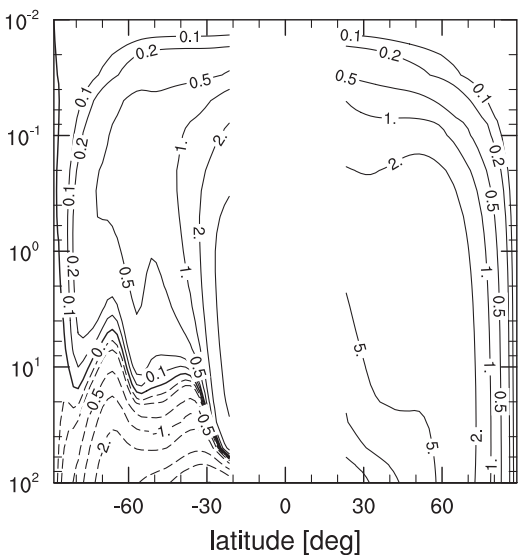

latitude [deg]
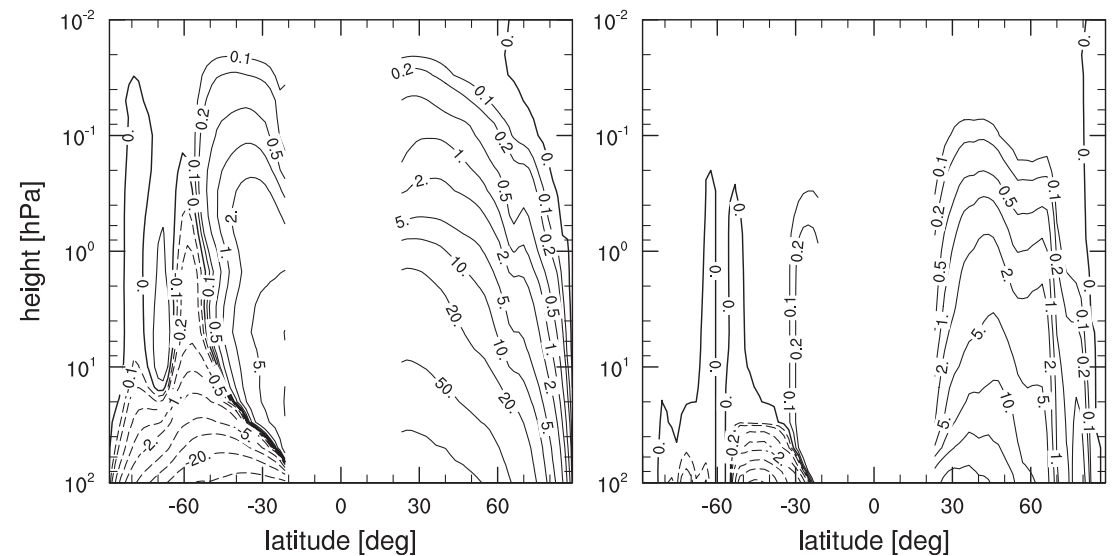

FIG. 2. The directly calculated mass streamfunction, the downward-control mass streamfunction with combined forcings from all types of wave drag (DWC), as well as the contribution of different wave drags separated via downward control (EPFD, OGWD, and NGWD) are presented for the present-day time slice of the L95 model configuration. Tropical latitudes are masked, as the downward-control principle is not applicable here.

upward mass flux from the preindustrial to the future climate state take place in $\mathrm{NH}$ winter, and the wave activity is expected to be the highest on the NH in DJF, the following investigations are focused on the DJF season.

In Fig. 2 the impact of different types of wave drag on the BDC pattern, studied through the downward-control principle, is evaluated in the L95 model configuration. The directly calculated total circulation pattern of the DJF-mean BDC is similar to the January-mean BDC obtained by Manzini and McFarlane (1998) with MAECHAM4. Also the parameterized gravity wave drag contribution shows the same main features in MAECHAM4 and ECHAM6.

The downward-control streamfunction reproduces the directly calculated streamfunction fairly well (Figs. $2 a, b)$. Only the vertical extent of the summer hemisphere's cell is slightly underestimated. This behavior is in agreement with the results presented by Okamoto et al. (2011), who applied the downward-control principle to their CCM output data. It is also conspicuous that the stratospheric winter circulation is primarily controlled by EPFD with second-order effects of OGWD. The NGWD mainly controls the mesospheric part of the meridional circulation and, together with the EPFD, builds up the summer upwelling branch in the stratosphere. These findings are in good agreement with the European Centre for Medium-Range Weather Forecasts (ECMWF) Interim Re-Analysis (ERA-Interim) dataset on all middle-atmospheric pressure levels covered by ERA-Interim (Okamoto et al. 2011).

In Fig. 3 the age of air, as derived from the different time-slice simulations, is compared to measurements of the age of stratospheric air in the midlatitudes carried out by Engel et al. (2009), which depict the longest available observational time series. In all model configurations the decrease in age of air is relatively small from the preindustrial to the present-day climate state, 


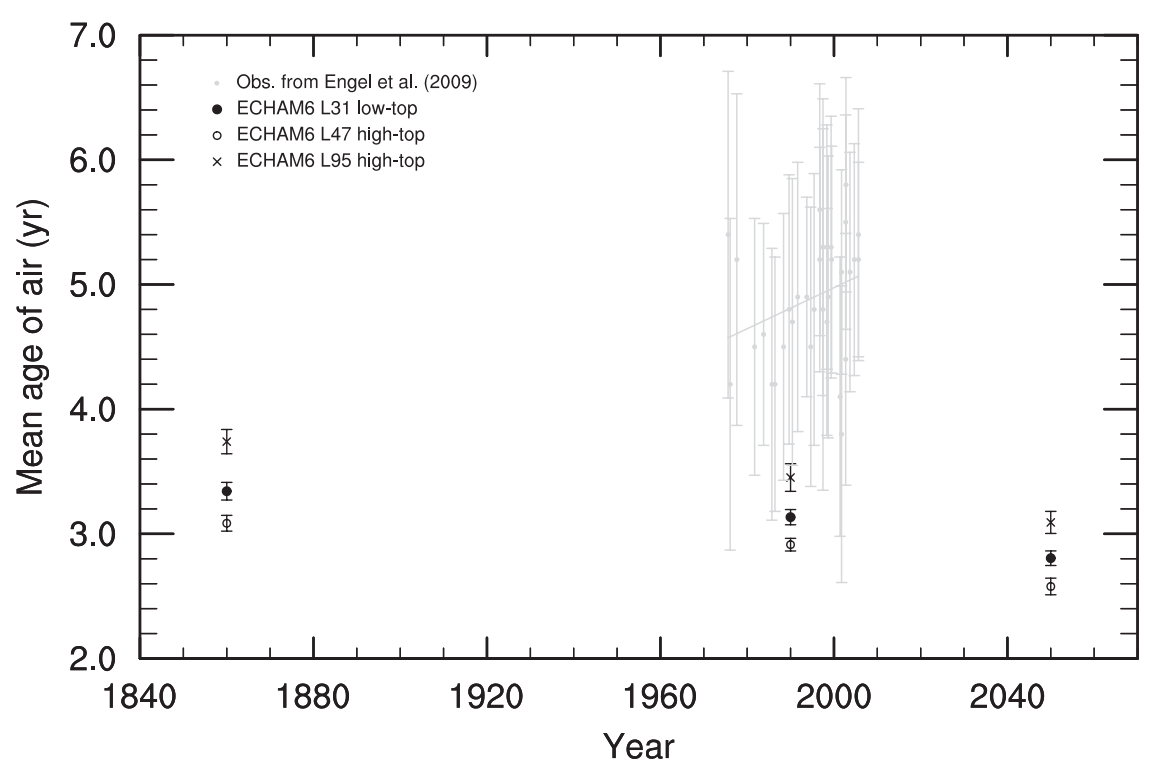

FIG. 3. Annual-mean age of air as derived from our model simulations is presented together with an observational reference dataset (gray; Engel et al. 2009). Error bars indicate one standard deviation for the model data and show the total error of the measurements. The solid line shows an unweighted linear regression computed from the observations.

followed by a more-rapid decrease in the future. This behavior coincides with a weak increase in tropical upwelling in the past and a stronger increase in the future (not shown), which is roughly in line with the relationship between reciprocal age of air and tropical upwelling found by Austin and Li (2006). The total age of air decrease from the preindustrial to the future climate state is $0.5-0.7 \mathrm{yr}$, depending on the model configuration (Fig. 3). Observational data (Engel et al. 2009) show a slight increase in age of air; however, the uncertainties in measurements are too high to disprove the model results (Garcia et al. 2011).

From Fig. 3 three main findings with regard to the age of air can be obtained, which we will focus on in the following sections:

(i) an offset for different model configurations in all time slices (see section 4a),

(ii) a similar change between the time slices in all model configurations (see section $4 b$ ), and

(iii) a difference between model and observational data (see section 5).

\section{a. The BDC in different model configurations}

Figure 3 shows that decreasing the vertical resolution in the high-top model from L95 to L47 leads to a difference in age of air of up to $20 \%$ in the midlatitudes. In the $\mathrm{L} 31$ model the obtained age of air in this region lies between the values associated with the two high-top model configurations, while the tropical upwelling is
$25 \%$ slower in the L31 model compared to the two hightop models (see Table 1).

The present-day mean age of air distribution in the L95 model configuration (Fig. 4a) reveals a comparable structure as the age of air derived from the different CCM simulations in Butchart et al. (2010), and looks similar to the age of air distribution obtained by Manzini and Feichter (1999) with the MAECHAM4 GCM.

The differences in mean age of air distributions between different model configurations are evaluated in Figs. 4b,c. Both the L47 as well as the L31 present-day time-slice simulations are compared to the same time slice in the L95 model configuration. In the high-top model decreasing the vertical resolution leads to a decrease in age of air at almost every grid point above the tropopause (Fig. 4b), which makes the BDC appear faster for lower vertical resolution. As the regions of the largest differences are located right above the extratropical tropopause, we attribute the origin of these differences primarily to higher numerical diffusion through the extratropical tropopause in the L47 model configuration due to lower vertical resolution. Additionally, increased recirculation due to higher vertical resolution could also contribute to larger age of air in the L95 model.

For the L31 model significantly older air compared to the L95 model configuration is found in the tropical lower stratosphere (Fig. 4c), indicating a significantly slower tropical upwelling in the L31 model. Regions of significantly younger air in the L31 model show up above the extratropical tropopause in both hemispheres, 
(a) Mean age of air [yr], present, L95

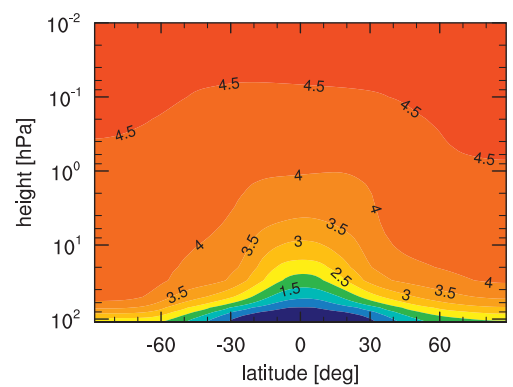

(b) Mean age of air [yr], present, L47-L95

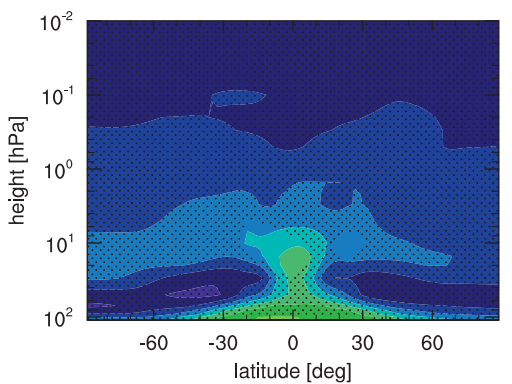

(c) Mean age of air [yr], present, L31-L95

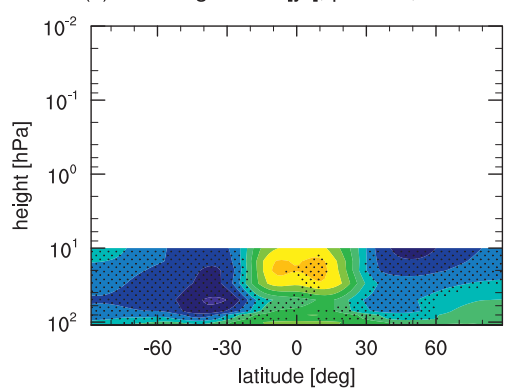

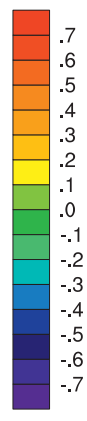

FIG. 4. Present-day annual-mean age of air as simulated in (a) the L95 model configuration is shown together with differences to (b) the L47 and (c) the L31 configurations of the model. Dotted areas indicate significance at the $95 \%$ confidence level after a $t$ test.

which may be the result of a slower BDC in the L31 model compared to the L95 version. As in the L47 model, increased numerical diffusion in the L31 model compared to the L95 configuration might also contribute to these differences.

The differences in mean age of air between the L31 and the high-top configurations are also reflected by the age spectrum. Figure 5 shows the age spectrum extracted at the tropical and extratropical stratosphere. The large abundance of young air transported recently from the troposphere to the stratosphere via tropical upwelling is clearly visible in both high-top model configurations. In the midlatitudes the age spectrum shows a much smoother distribution, which originates from quasi-horizontal transport and mixing (Waugh and Hall 2002). In the L31 model, however, the age spectrum shows much less difference between the tropical and the extratropical stratosphere (Fig. 5). Here the significantly lower tropical upwelling leads to a relatively larger impact of horizontal transport and mixing already during the ascent of air in the tropics, causing the fresh young air to be distributed to higher latitudes much earlier. In the high-top model, increasing the vertical resolution leads to a slight shift of the age spectrum toward older ages. This shift could reflect both increased recirculation of air and reduced numerical diffusion through the tropopause in the L95 model configuration.

To evaluate the impact of the model configuration on the BDC pattern, the present-day residual streamfunctions in both the L47 (Fig. 6) as well as the L31 model (Fig. 7) are compared to the associated streamfunction in the L95 model configuration (Fig. 2). The difference in the directly calculated streamfunction reveals that decreasing the vertical resolution in the high-top model causes an acceleration of the residual circulation in the stratosphere and a deceleration in the (a) Age spectrum at $20 \mathrm{hPa}, 10 \mathrm{~N}$

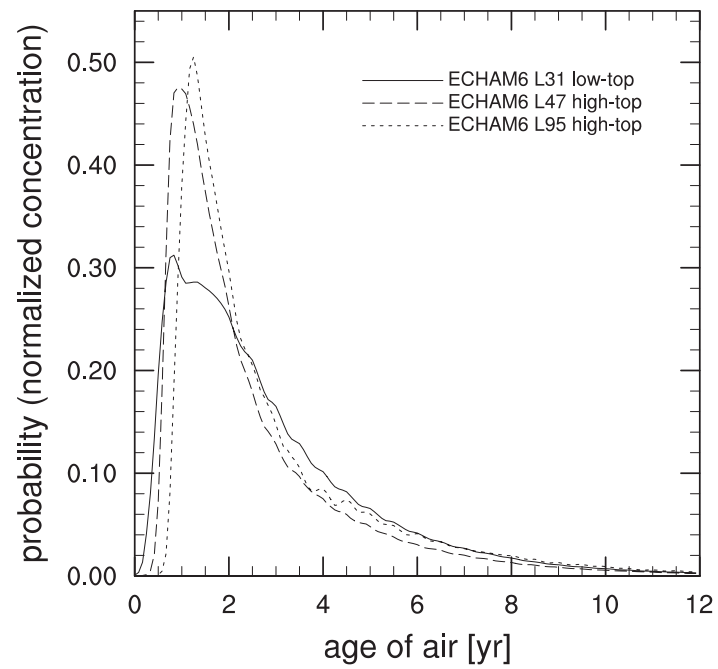

(b) Age spectrum at $10 \mathrm{hPa}, 51 \mathrm{~N}$

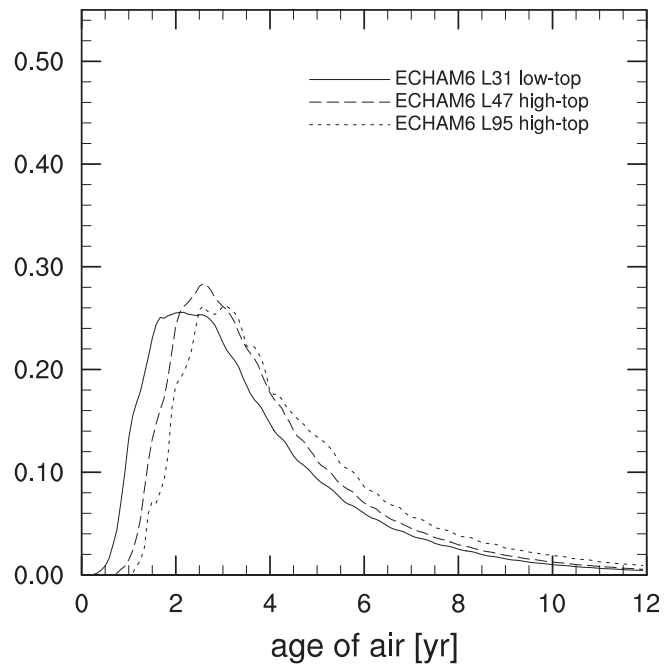

FIG. 5. Present-day age of air spectra extracted at (a) the tropical $\left(20 \mathrm{hPa} ; 10^{\circ} \mathrm{N}\right)$ and (b) the extratropical stratosphere $\left(10 \mathrm{hPa} ; 51^{\circ} \mathrm{N}\right)$ are shown for all model configurations. 
(a) Streamfunction diff. [kg/m/s], DJF

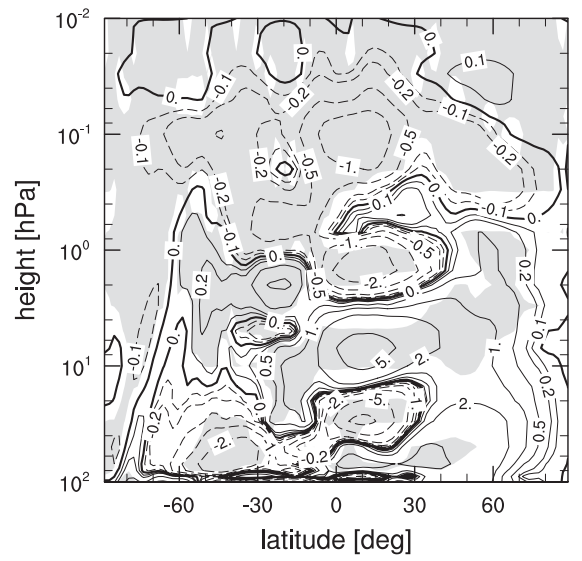

(c) EPFD streamf. diff. [kg/m/s], DJF

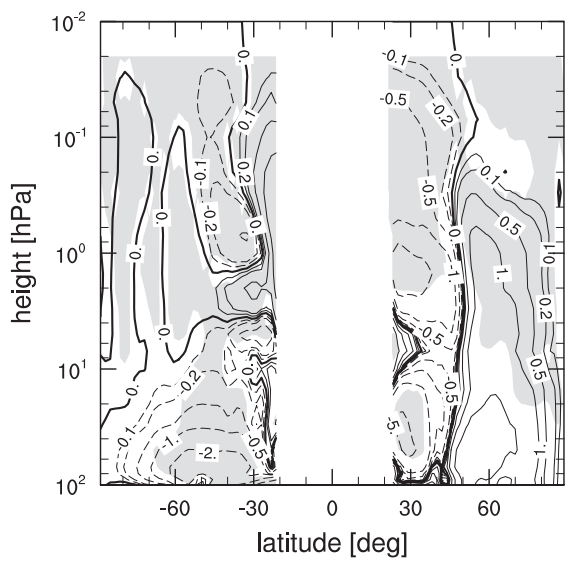

(b) DWC streamf. diff. [kg/m/s], DJF

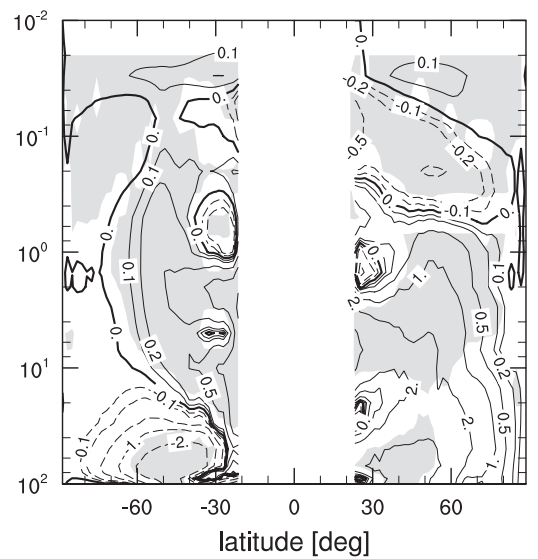

(d) OGWD streamf. diff. [kg/m/s], DJF

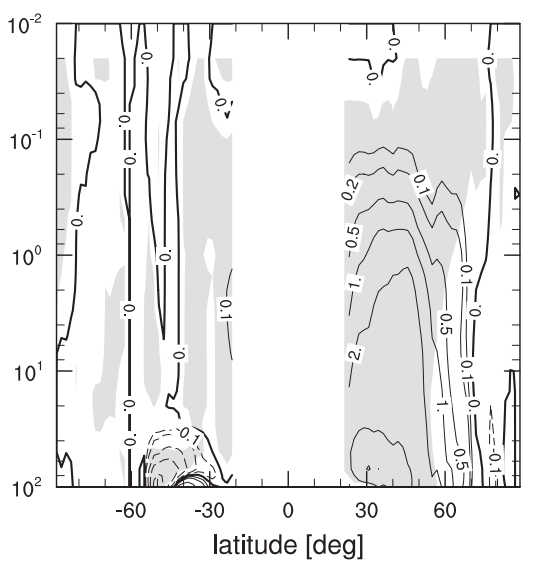

(e) NGWD streamf. diff. [kg/m/s], DJF

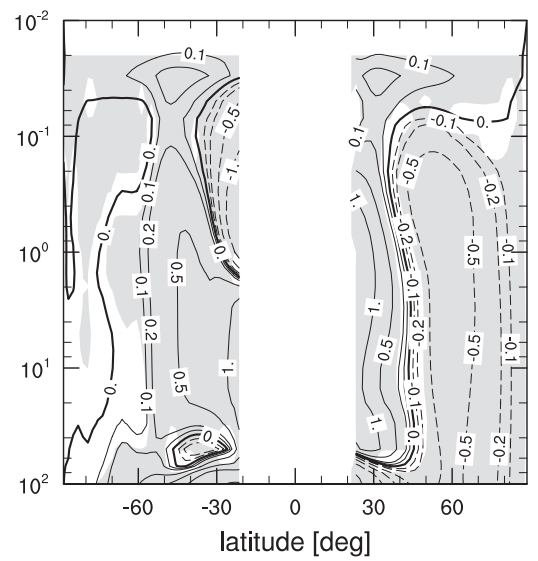

FIG. 6. Streamfunction difference for the present-day time slice between different vertical resolutions of the high-top model (L47 L95) is shown. The directly calculated streamfunction, the downward-control streamfunction with combined forcings from all types of wave drag (DWC), as well as the contribution of different wave drags separated via downward control are presented (EPFD, OGWD, and NGWD). Shaded areas indicate significance at the $95 \%$ confidence level after a $t$ test. Note that after application of the downward-control principle there are no significant differences in the uppermost model layer, as here the streamfunction is zero by definition.

mesosphere. Both EPFD as well as OGWD are identified as the origin of the difference in stratospheric circulation pattern. In the upper stratosphere and mesosphere the difference in the BDC is induced by combined effects of EPFD and NGWD (Fig. 6). In the tropical part of the circulation, differences are particularly likely to be caused by the secondary meridional circulation induced by the QBO.

Comparing the BDC pattern in L31 and L95 model configurations, a three-cell structure in streamfunction differences (Fig. 7a) is obtained. Generally, the BDC is slower in the L31 configuration; however, a polar cell shows up in the $\mathrm{NH}$, indicating a faster BDC in the northern high latitudes. Figure $7 \mathrm{~b}$ also shows that this polar cell does not appear in the streamfunction differences derived via downward control. Both EPFD and OGWD contribute to the weaker BDC at all latitudes in the
L31 configuration of the model. As the NGWD is not incorporated into the L31 model, and yields a positive contribution to the BDC in the $\mathrm{NH}$ polar stratosphere in the L95 model (Fig. 2e), an additional force must be acting in the L31 model configuration, which cannot be inferred by downward control.

A close-up of the streamfunction on the 70-hPa pressure surface in the L31 model (Fig. 8a) depicts the conspicuous difference between the directly calculated streamfunction and the downward-control streamfunction in the northern high latitudes. As the impact of the additional force is particularly strong in the uppermost layers of the L31 model, we identify the enhanced horizontal diffusion (see section 3 ) as the origin of this artificial force. On the other hand, the hemispheric difference in the $70-\mathrm{hPa}$ DJF-mean streamfunction is apparent in all model configurations. In the two high-top 
(a) Streamfunction diff. [kg/m/s], DJF

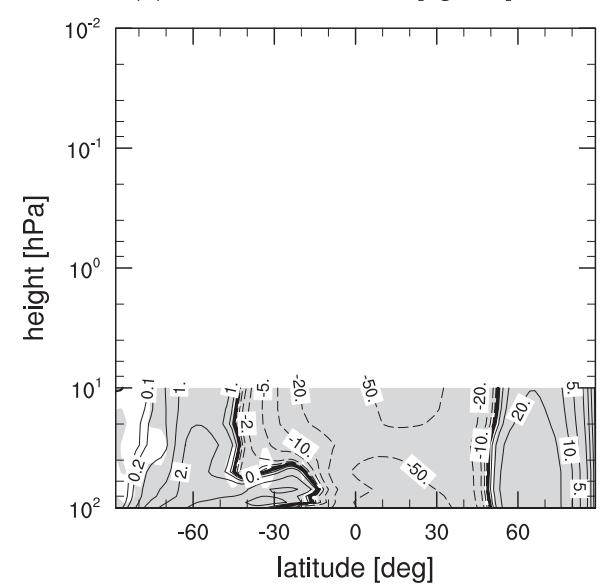

(c) EPFD streamf. diff. [kg/m/s], DJF

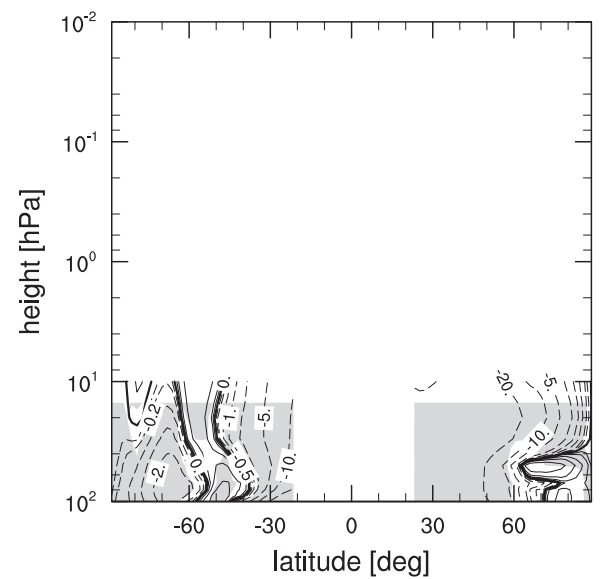

(b) DWC streamf. diff. [kg/m/s], DJF

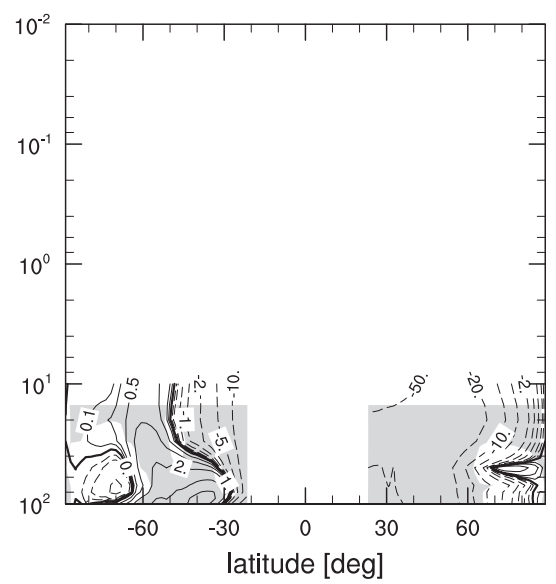

(d) OGWD streamf. diff. [kg/m/s], DJF

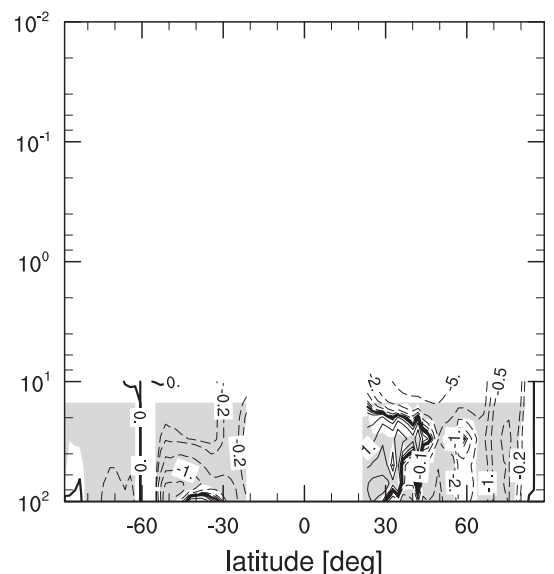

FIG. 7. Streamfunction difference for the present-day time slice between different vertical extents of the model (L31 - L95) is shown. The directly calculated streamfunction, the downwardcontrol streamfunction with combined forcings from all types of wave drag (DWC), and the contribution of different wave drags separated via downward control (EPFD and OGWD) are presented. Shaded areas indicate significance at the $95 \%$ confidence level after a $t$ test.

models the downward-control principle yields a good approximation to the direct streamfunction at all extratropical latitudes (Figs. 8b,c). Considering that generally the amplitudes of resolved waves are still large at the lid of the L31 model $(10 \mathrm{hPa})$, while there is negligible resolved wave momentum left at the lid of the L47 and L95 models $(0.01 \mathrm{hPa})$, it is coherent that the effect of damping the resolved wave momentum into the upper model layers is much more prominent in the L31 model. Since in the summer hemisphere planetary wave momentum flux is negligible above the middle stratosphere, the difference between the directly calculated streamfunction and the downward-control streamfunction is small also in the L31 model (Fig. 8a). In the northern high latitudes the difference of the directly calculated DJF-mean streamfunction and the downward-control streamfunction with combined forcings from all types of wave drag can be used to roughly quantify the impact of the enhanced horizontal diffusion on the residual circulation.

Figure 8 also shows an offset in the 70-hPa streamfunction for the different vertical extents of the model. In the L31 model version the streamfunction is roughly $25 \%$ weaker than in the L95 model configuration. This behavior is reflected by the total upward mass flux (see Table 1 and Fig. 9), which is also consistent with the differences in mean age of air above the tropical tropopause (Fig. 4c). In the midlatitudes, the additional force originating from enhanced horizontal diffusion has accelerated the air parcels in the L31 model, so that the age of air obtained from the L31 model in the midlatitudes lies between the values associated with the two high-top models (Fig. 3). 
(a) Streamfunction, $70 \mathrm{hPa}$, DJF, L31

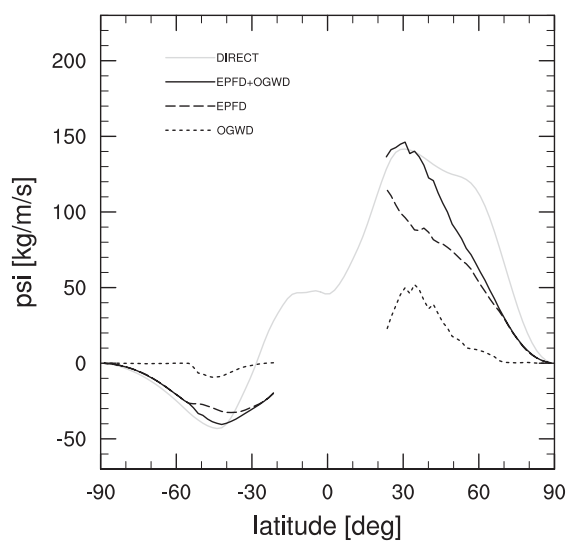

(b) Streamfunction, $70 \mathrm{hPa}$, DJF, L47

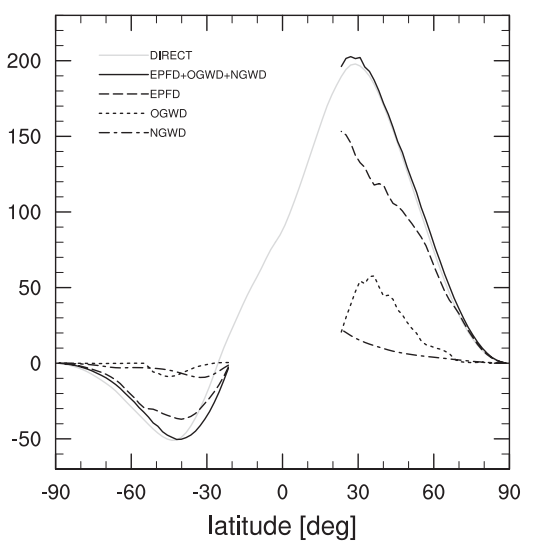

(c) Streamfunction, $70 \mathrm{hPa}$, DJF, L95

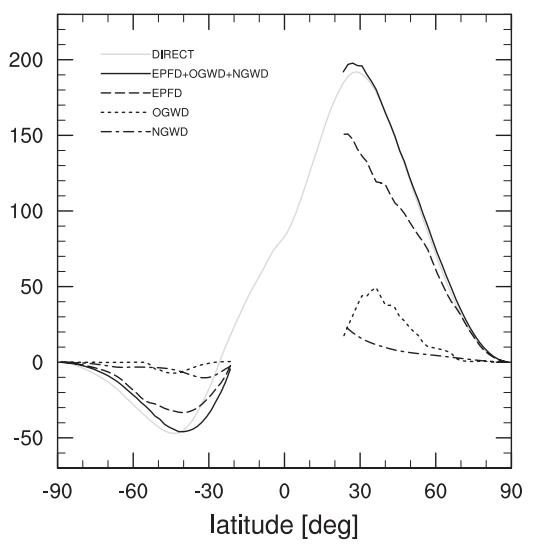

FIG. 8. The DJF streamfunction at $70 \mathrm{hPa}$ with contributions of different types of wave drag, as derived from the present-day time slice in the (a) L31, (b) L47, and (c) L95 model configurations, is presented.

The directly calculated streamfunction, simulated with different vertical extents of the model, shows a conspicuous difference in the tropics. While in the hightop model a relatively uniform tropical upwelling is simulated between the turnaround latitudes, the streamfunction is independent of the latitude in a confined latitude band close to the equator in the low-top model (Fig. $8 \mathrm{a})$, indicating a region of no tropical upwelling. It is so far not clear which mechanism causes this behavior. Both the NGWD, which is important for the forcing of the easterly phase of the QBO in the L95 model (Giorgetta et al. 2006) and absent in the L31 model, as well as the modified horizontal diffusion scheme (see section 3 ) in the low-top model might play an important role here.

Both high-top model configurations show comparable streamfunctions and upward mass fluxes (Figs. 8b,c and $9 \mathrm{~b}, \mathrm{c})$. The relatively small difference of less than $5 \%$ in the total upward mass flux at $70 \mathrm{hPa}$ (see Table 1 and
Figs. $9 \mathrm{~b}, \mathrm{c}$ ) is caused by both resolved and unresolved wave drags with comparable relative contributions. The total upward mass flux in the L47 and L95 models is comparable in magnitude to the mass flux derived by Okamoto et al. (2011) and McLandress and Shepherd (2009) for similar periods in their CCMs. As in McLandress and Shepherd (2009) and the multimodel average of Butchart et al. (2011), the resolved wave drag yields the main contribution to the total upward mass flux at $70 \mathrm{hPa}$. Also the relative contributions of resolved and unresolved wave drag to the total upward mass flux are similar to the results of their CCM simulations. However, the contribution of resolved wave drag is higher in ECHAM6 than in the CCM used by Okamoto et al. (2011), which is compensated by a larger OGWD contribution in their model. As the horizontal resolution used by Okamoto et al. (2011) is lower than in our simulations and, thus, fewer waves are resolved in their model, the difference (a) $70 \mathrm{hPa}$ upward mass flux, DJF, L31

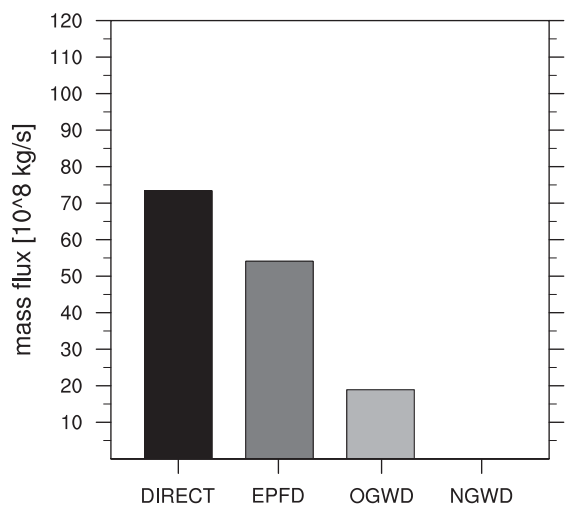

(b) $70 \mathrm{hPa}$ upward mass flux, DJF, L47

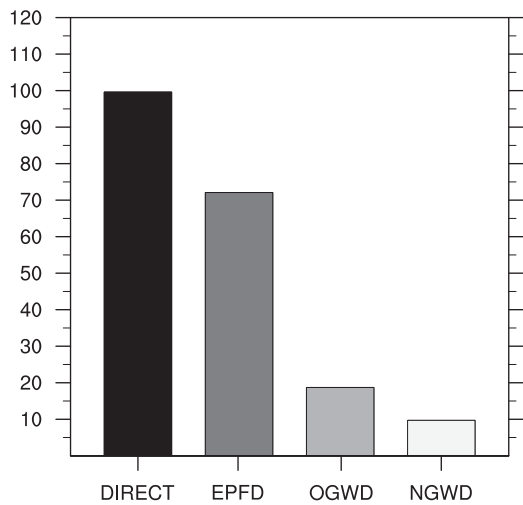

(c) $70 \mathrm{hPa}$ upward mass flux, DJF, L95

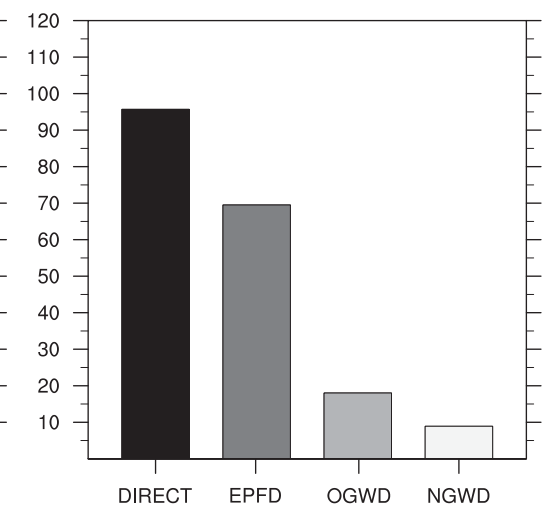

FIG. 9. The DJF upward mass flux through the 70-hPa pressure surface together with contributions of different types of wave drag, as derived from the present-day time slice in the (a) L31, (b) L47, and (c) L95 model configurations, is presented. 
(a) Mean age of air [yr], fut.-preind., L31

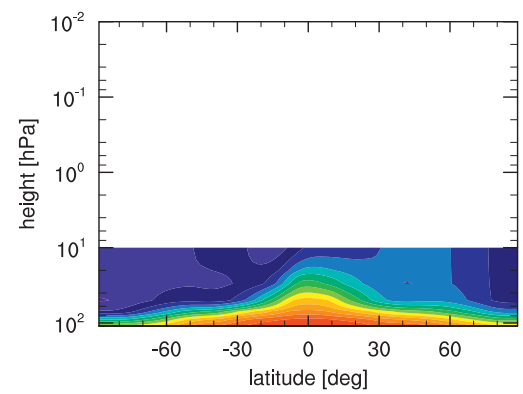

(b) Mean age of air [yr], fut.-preind., L47

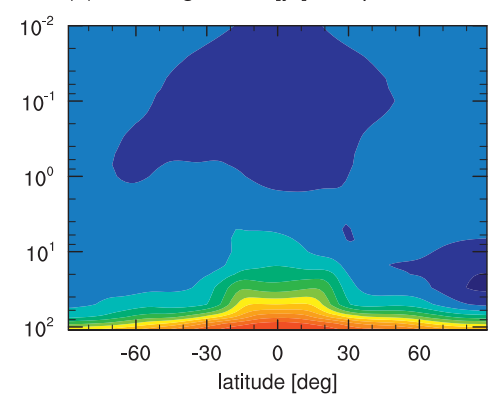

(c) Mean age of air [yr], fut.-preind., L95

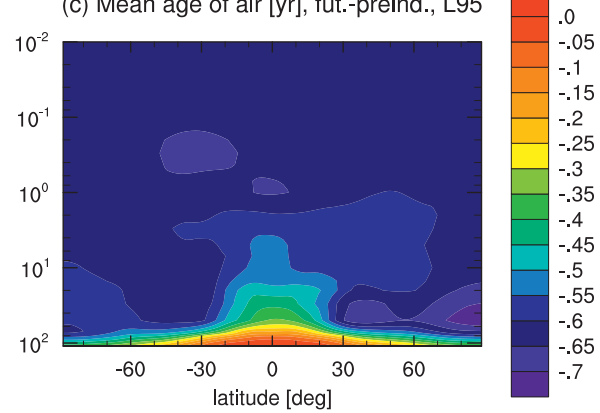

FIG. 10. The annual-mean age of air difference between the preindustrial and the future climate state, as simulated in the (a) L31, (b) L47, and (c) L95 model configurations, is presented. In all model setups the differences are significant at the $95 \%$ confidence level in the entire model domain from $110 \mathrm{hPa}$ upward.

in contribution of different types of wave drag to the total upward mass flux could also be related to the different model setup.

A comparison of the mass fluxes obtained from the present-day time-slice simulation in the different model configurations (Fig. 9) to ERA-Interim data, as evaluated by Seviour et al. (2012) and Okamoto et al. (2011), implies that the upward mass flux is overestimated in the high-top model by roughly $20 \%$, which is due to an overestimation of the EPFD contribution. On the other hand, the OGWD contribution to the upward mass flux is much lower in all model configurations compared to ERA-Interim data (Okamoto et al. 2011). In the L31 configuration the total upward mass flux is comparable to the values derived from ERA-Interim data. The reason for the difference between the models and ERAInterim data in the relative contributions of resolved and unresolved wave drags to the upward mass flux could be related to the coarser horizontal resolution of the ERAInterim dataset used by Okamoto et al. (2011).

The model results evaluated in this section showed many similarities in the BDC simulated by the L47 and L95 models. However, in the low-top model the tropical upwelling at $70 \mathrm{hPa}$ is roughly $25 \%$ slower, and the enhanced horizontal diffusion leads to a distinct behavior of the BDC in the upper model levels (starting at $90 \mathrm{hPa}$ upward) compared to the high-top models.

\section{$b$. The simulated BDC change in different model configurations}

The mean age of air decreases from the preindustrial to the future climate state in the entire model domain above the tropopause (Fig. 10). This decrease is significant at the $95 \%$ confidence level in every model configuration and indicates a strengthening of the BDC. The magnitude of the change in age of air depends on both height and latitude but is generally smallest in the L47 configuration of the model. The distribution of the age change resembles in all configurations roughly the distributions obtained by Butchart et al. (2010) for several CCMs. The resemblance to their multimodel mean is highest in the L47 and L95 configurations, where the strongest age decrease occurs in the $\mathrm{NH}$ lower stratosphere. In the L95 model, here the air is more than 270 days younger in the future than in the preindustrial state. Even though the L31 model does not resolve the entire stratosphere, a similar change in age of air as in the high-top configurations shows up. However, here the largest change is found in the SH. Generally, the change is larger in the L31 model compared to the L47 configuration, but smaller than in the L95 model version.

Streamfunction changes derived from the two hightop model configurations are very similar in the entire model domain (not shown). Except for slight differences in the tropics, which could be QBO related, the change pattern is comparable between the two configurations.

The L31 model shows a change in the circulation pattern, which is similar in sign to the change in the L95 configuration (Fig. 11). Both model versions show a strengthening of the BDC. Contributions of resolved and unresolved waves also have the same sign almost everywhere in the stratosphere, independent of the vertical extent of the model. Resolved waves consistently cause a BDC strengthening everywhere in the lower stratosphere as well as in the extratropical middle and upper stratosphere. In the subtropical middle and upper stratosphere, however, their impact leads to a more complex change in the circulation pattern. The change in unresolved wave drag, on the other hand, contributes to the BDC strengthening in the tropics and subtropics but has a decelerating effect in the high latitudes of the winter hemisphere. The magnitude of the change in streamfunction and its attribution to different wave forcings, on the other hand, differ among the model configurations. 
(a) Streamfunction diff. [kg/m/s], DJF

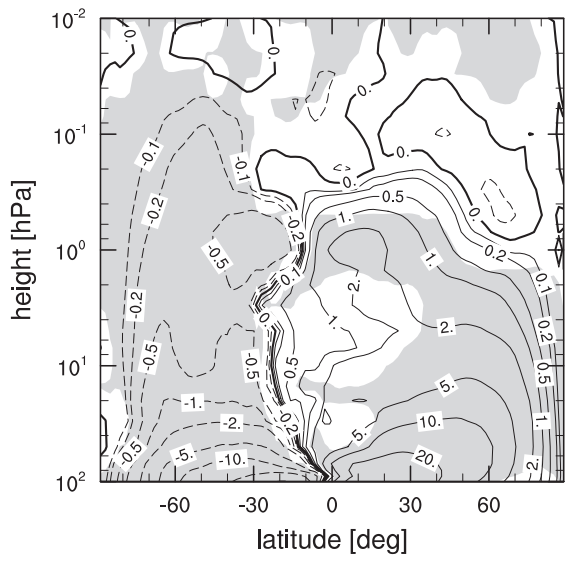

(c) EPFD streamf. diff. $[\mathrm{kg} / \mathrm{m} / \mathrm{s}]$, DJF

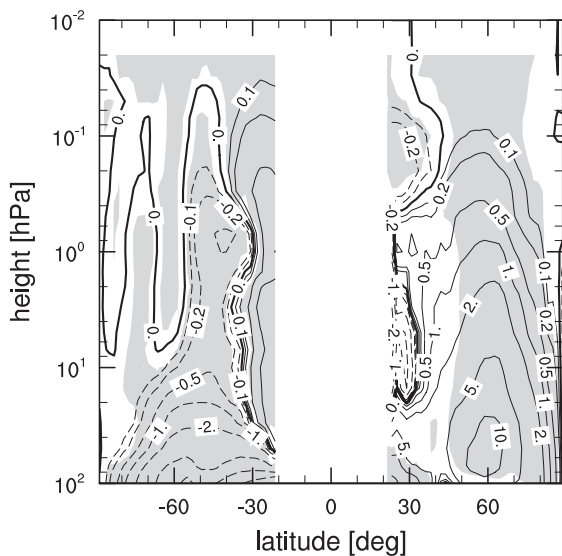

(f) EPFD streamf. diff. [kg/m/s], DJF

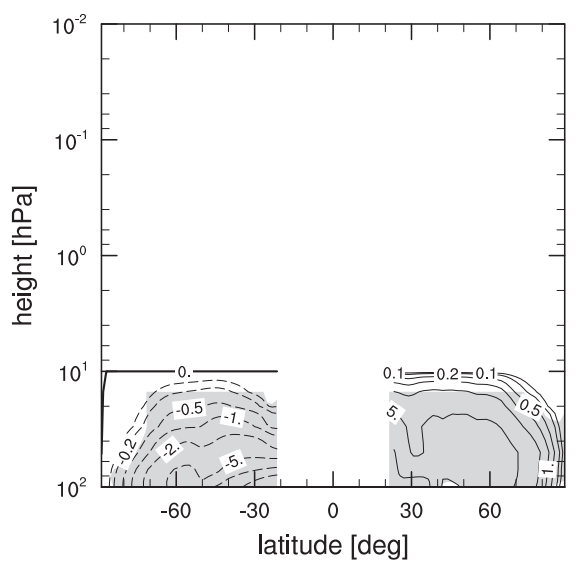

(b) Streamfunction diff. [kg/m/s], DJF

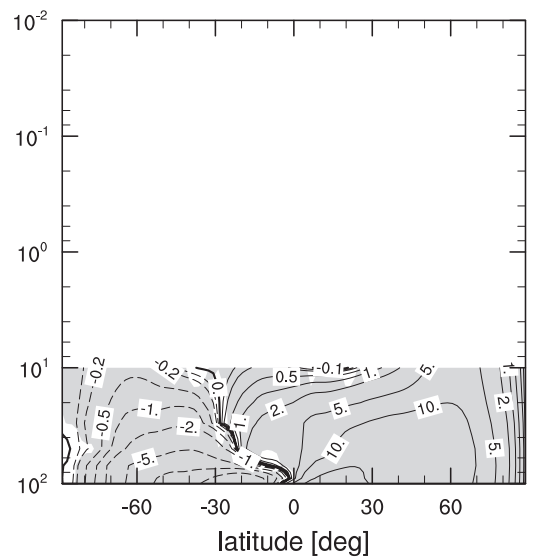

(d) OGWD streamf. diff. [kg/m/s], DJF

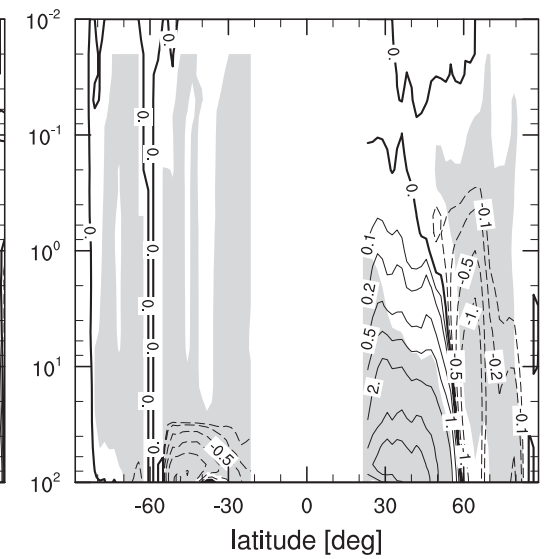

(g) OGWD streamf. diff. [kg/m/s], DJF

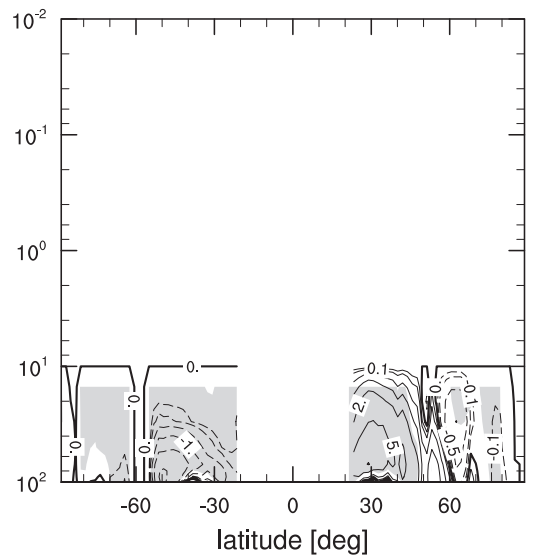

(e) NGWD streamf. diff. [kg/m/s], DJF

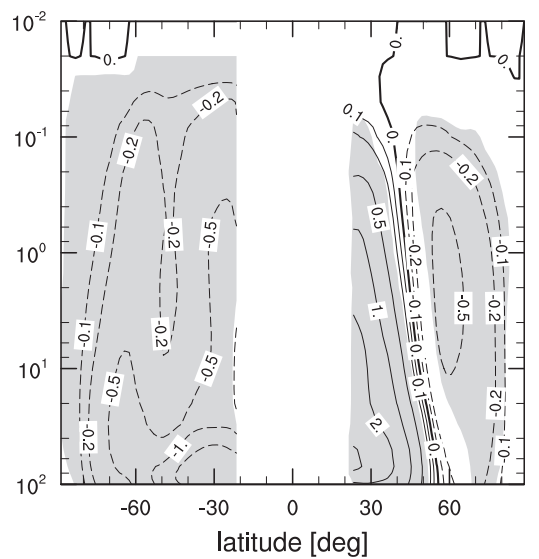

latitude [deg]

FIG. 11. The mass streamfunction difference between preindustrial and future climate states, as derived from the L95 model configuration and for the L31 model version, is shown. (a),(b) The directly calculated mass streamfunction and (c)-(g) the contribution of different wave drags separated via downward control are presented. Shaded areas indicate significance at the $95 \%$ confidence level after a $t$ test.

The BDC acceleration, as obtained from the change in pattern of the residual circulation, is in agreement with the study of Karpechko and Manzini (2012), who compared the response of doubled $\mathrm{CO}_{2}$ concentrations in low-top and high-top versions of ECHAM5. However, Karpechko and Manzini (2012) found in both model configurations a BDC deceleration in the NovemberDecember-mean streamfunction in the northern high 
(a) Streamfunction diff., $70 \mathrm{hPa}$, DJF, L31

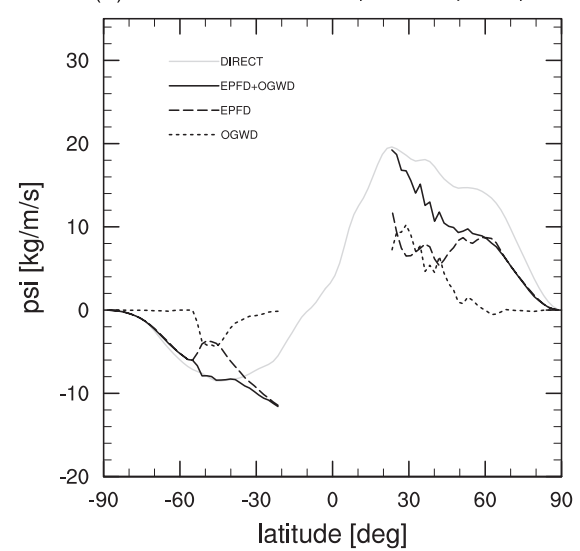

(b) Streamfunction diff., $70 \mathrm{hPa}$, DJF, L47

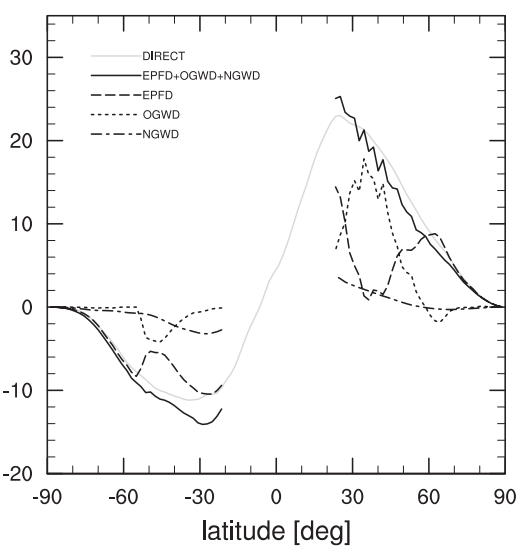

(c) Streamfunction diff., $70 \mathrm{hPa}$, DJF, L95

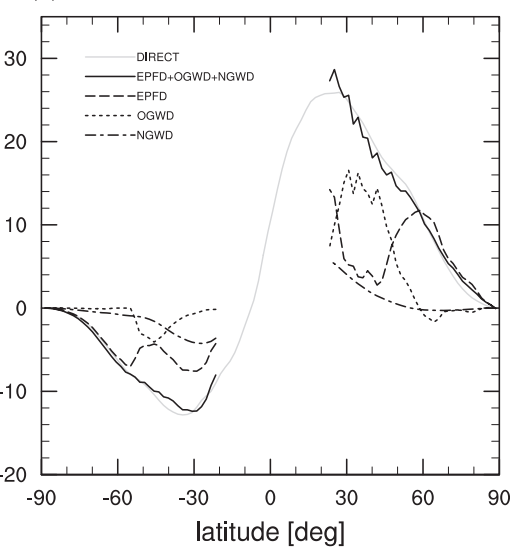

FIG. 12. The streamfunction difference between preindustrial and future climate states together with contributions of different types of wave drag, as derived from the (a) L31, (b) L47, and (c) L95 model configurations, is presented.

latitudes, which is absent in the DJF-mean streamfunction of our simulations. On the other hand, the pattern of the BDC acceleration (Fig. 11) compares fairly well to the findings of McLandress and Shepherd (2009). Okamoto et al. (2011), however, found an additional cell of deceleration in the summer hemispheric subtropics of the middle stratosphere, which we do not observe in our simulations.

The change in streamfunction at the $70-\mathrm{hPa}$ pressure surface as derived from the different model configurations (Fig. 12) supports the findings obtained from the age of air (Fig. 10). The L95 model simulates the strongest change in streamfunction. For the L31 model the streamfunction change is weak compared to the high-top model configurations, and an impact of the damping of resolved waves is again visible (Fig. 12). Another conspicuous finding here is that in the midlatitudes the EPFD contribution to the streamfunction change drops, while the OGWD contribution seems to compensate this drop. This compensation between EPFD and OGWD shows up in every model configuration and is also visible in the CCM used by McLandress and Shepherd (2009).

As already indicated by the streamfunctions, the total upward mass flux change from the preindustrial to the future climate state at $70 \mathrm{hPa}$ is the same in sign but different in magnitude for different model configurations (Fig. 13). The EPFD contribution is more or less the same in both high-top model configurations, while slightly higher OGWD and NGWD contributions lead to a total mass flux change, which is roughly $15 \%$ larger in the L95 configuration. In the L31 model the total mass flux change at $70 \mathrm{hPa}$ is roughly $30 \%$ lower than in the $\mathrm{L} 95$ model. However, taking into account that the total upward mass flux is generally also about $25 \%$ lower in the L31 model than in the high-top model (Fig. 9), this is not a very surprising result. The most prominent finding here is that the origin of the change is primarily (a) 70hPa mass flux, fut.-preind., DJF, L31

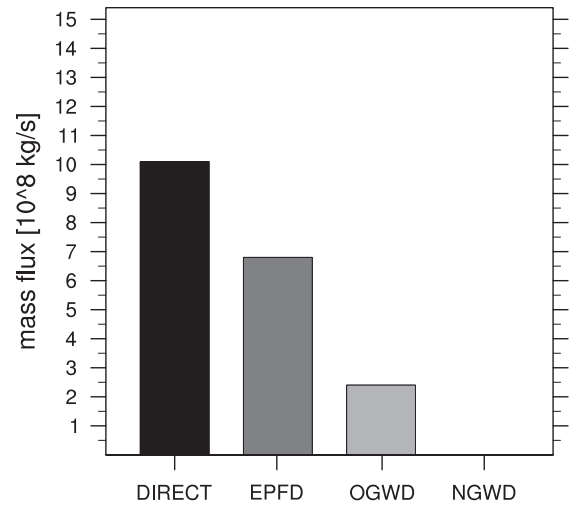

(b) 70hPa mass flux, fut.-preind., DJF, L47

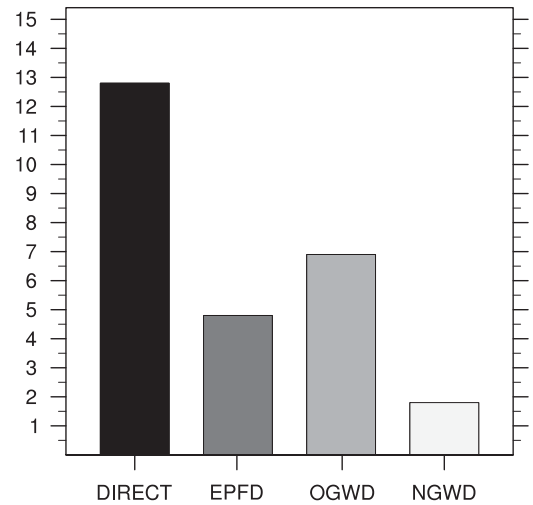

(c) 70hPa mass flux, fut.-preind., DJF, L95

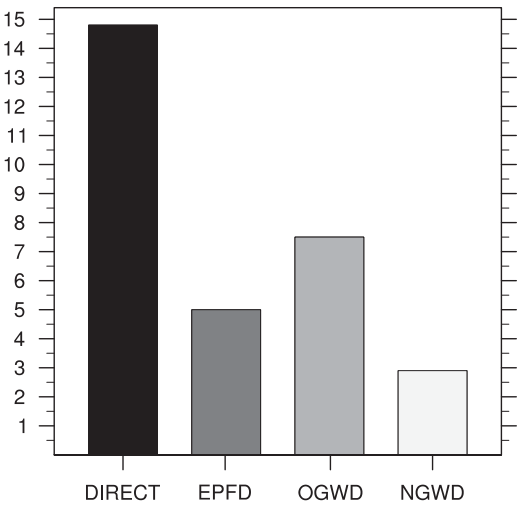

FIG. 13. The 70-hPa DJF upward mass flux difference between preindustrial and future climate states together with contributions of different types of wave drag, as derived from the (a) L31, (b) L47, and (c) L95 model configurations, is presented. 
(a) Change in DJF trop. upw., fut.-preind., L31

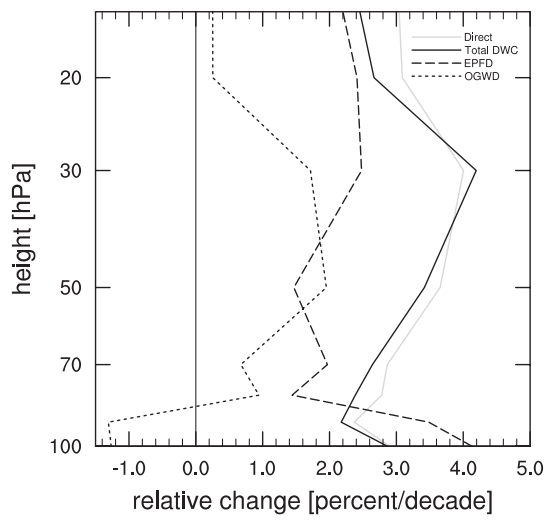

(b) Change in DJF trop. upw., fut.-preind., L47

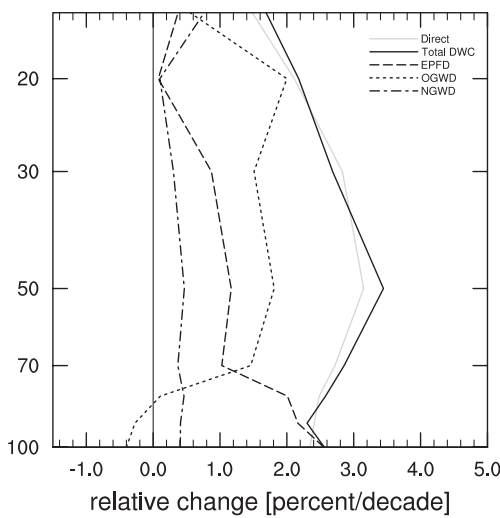

(c) Change in DJF trop. upw., fut.-preind., L95

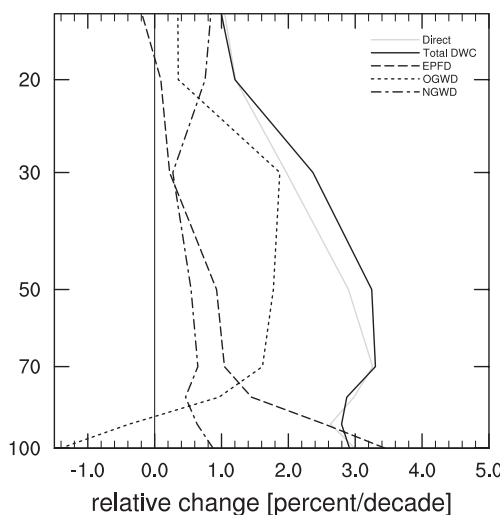

FIG. 14. Relative change in DJF tropical upwelling from the preindustrial to the future climate state, together with contributions of different types of wave drag, as derived from the (a) L31, (b) L47, and (c) L95 model configurations, is presented.

the EPFD in the L31 model, while the OGWD contribution is predominant for the upward mass flux change at $70 \mathrm{hPa}$ in both high-top model configurations. According to Eq. (6) the sum of the absolute values of the streamfunction at the turnaround latitudes, located at roughly $30^{\circ} \mathrm{N}$ and $43^{\circ} \mathrm{S}$ (Fig. 8), gives the total upward mass flux. While the difference in streamfunction changes at $43^{\circ} \mathrm{S}$ is small among the model configurations (Fig. 12), the behavior of the streamfunction at the northern turnaround latitude $\left(30^{\circ} \mathrm{N}\right)$ is crucial for the different origin of the streamfunction change in low-top and high-top model versions. At $30^{\circ} \mathrm{N}$, the OGWD yields the main contribution to the streamfunction change in the hightop models, causing the mass flux in the L47 and L95 models to be OGWD dominated (Fig. 13). On the other hand, in the low-top model OGWD and EPFD contributions to the streamfunction change at $30^{\circ} \mathrm{N}$ are comparable. Thus, the EPFD-dominated streamfunction change in the SH causes the mass flux to be EPFD dominated in the L31 model.

In McLandress and Shepherd (2009) as well as in Garcia and Randel (2008) the EPFD contribution to the increase in the DJF-mean upward mass flux through the $70-\mathrm{hPa}$ pressure surface was found to be roughly $70 \%$. In both of these studies high-top CCMs were used, which contributed to the CCMVal activity of SPARC. Their result is in good agreement with our L31 simulations (Fig. 13); however, it contradicts the findings obtained from our high-top simulations. Garny et al. (2011) also found an EPFD-dominated 70-hPa upward mass flux increase in their low-top CCM. On the other hand, Butchart et al. (2010) found a large spread in the wave type contributions to the BDC trend simulated by the different CCMVal-1 models.

To see how this behavior changes with height, the contribution of the different types of wave drag to the relative change in tropical upwelling is evaluated in the vertical profile (Fig. 14). EPFD is identified as the main contributor to the change in tropical upwelling in the lowermost stratosphere (75-100 hPa) in every model configuration. From $100 \mathrm{hPa}$ upward, the EPFD contribution decreases with height in all model versions. This decrease is compensated by an increase in the OGWD contribution. In the two high-top models the OGWD exceeds the EPFD contribution at roughly $75 \mathrm{hPa}$, and is the primary contributor to the upward mass flux increase up to $10 \mathrm{hPa}$. In the low-top model the OGWD exceeds the EPFD contribution only in a small altitude range at around $50 \mathrm{hPa}$. Above $50 \mathrm{hPa}$, here the EPFD is again the primary contributor to the increase in tropical upwelling.

The increase in parameterized wave drag in the middle stratosphere $(10-70 \mathrm{hPa})$ as well as the increase in resolved wave drag in the lower stratosphere $(70-100 \mathrm{hPa})$ are consistent with an upward shift of the breaking level of orographic gravity waves and the critical layers for resolved wave dissipation, caused by the modified zonalmean zonal wind field (Fig. 1).

While the model results discussed in section 4 a showed that the relative wave drag contributions to the driving of the $\mathrm{BDC}$ are similar among the model configurations, the evaluation of BDC changes indicated that simulations with different vertical model extents produce changes comparable in sign and magnitude, which originate from different causes.

\section{Summary and conclusions}

Results of 50-yr sensitivity simulations for different climate states, performed with the state-of-the-art GCM ECHAM6 in different model configurations, have shown several similarities in the appearance of the BDC among the applied configurations of the model. The BDC pattern 
is qualitatively similar, independent of vertical resolution and vertical extent of the model. Even the relative contribution of resolved and unresolved waves to the driving of the total upward mass flux from the troposphere to the stratosphere is comparable. However, we find the 70-hPa upward mass flux to be lower by roughly $25 \%$ in the L31 configuration than in the high-top configurations of the model. When the air is close to the lid of the L31 model, an artificial force causes an additional acceleration, making the BDC in the mid- and high latitudes appear as strong as in the high-top configurations of the model. In fact, here values of the mean age of air in the L31 model lie between those of the two high-top model configurations. The artificial force acting in the L31 model originates from the horizontal diffusion scheme, which was modified in order to damp the momentum carried by the resolved waves into the upper model layers to avoid wave reflection at the model lid. The reduced EPFD contribution to the driving of the upward mass flux in the lower stratosphere, together with a second-order contribution of the missing NGWD in the L31 configuration, cause the slower tropical upwelling in the low-top configuration of ECHAM6.

The slower tropical upwelling in the L31 configuration is also clearly reflected by the age spectrum. Compared to the total upward mass flux derived from ERA-Interim data, however, the L31 configuration simulates the most realistic tropical upwelling velocity at $70 \mathrm{hPa}$.

Increasing the vertical resolution in the high-top model, on the other hand, results in a slightly slower BDC. The total upward mass flux at $70 \mathrm{hPa}$ is reduced by roughly $5 \%$, and the mean age of stratospheric air increases by about $20 \%$ in the midlatitudes. We attribute the origin of this difference in age of air among the two high-top models primarily to the reduced numerical diffusion through the tropopause in the L95 model configuration. By inducing the secondary meridional circulation (Plumb and Bell 1982) the internally generated QBO in the L95 model may be another source for the difference in the BDC pattern among the two high-top model configurations.

All configurations of the model have shown a qualitatively similar BDC change between the different time slices. The weakest increase in strength of the subtropical jets is simulated in the L31 configuration of ECHAM6, coinciding with the weakest response in the 70-hPa upward mass flux in this model setup. Nevertheless, we find a significant increase in tropical upwelling through the tropopause in all model configurations. We emphasize here, however, that BDC changes obtained from different time-slice simulations, each performed under stationary boundary conditions, cannot necessarily be considered to be directly comparable to trends derived from transient climate simulations or observational time series.

We confirm this picture of a BDC strengthening qualitatively for all applied configurations of the ECHAM6 GCM. This result is consistent with the findings of Karpechko and Manzini (2012), who analyzed the BDC change from the present-day climate to a climate under doubled $\mathrm{CO}_{2}$ concentrations as simulated by the ECHAM5 GCM in low-top and high-top model configurations. In both ECHAM6 L47 and L95 models the increase in 70-hPa DJF upward mass flux is dominated by an increase in the parameterized wave drag contribution. Although the upward mass flux was found to be largest in the L47 model, the highest increase in upward mass flux is simulated in the L95 version of the model. The parameterized wave drag causes a slightly larger increase in the upward mass flux in this model version than in the L47 configuration. In the L31 model, however, the change is generally smaller by roughly $30 \%$ compared to the L95 configuration and is dominated by an increase in the contribution of the resolved wave drag. Thus, we conclude that although the origin of the change in tropical upwelling varies with the vertical extent of the model, the ECHAM6 low-top model simulates a qualitatively similar BDC response as the two high-top configurations.

The reason for the dependence of the wave drag contribution on the vertical model extent is likely to be related to the treatment of the wave momentum flux at the model lid. Shaw and Shepherd (2007) found that the conservation of angular momentum by depositing the gravity wave momentum flux in the upper model levels has a significant impact on the downwelling induced by gravity wave drag. Depositing the orographic gravity wave momentum flux in the upper levels of the ECHAM6 GCM could therefore yield significant implications for the wave drag contribution to the tropical upwelling in the low-top configuration.

Evaluating the vertical profile of the zonal-mean change in DJF tropical upwelling, an increase from the preindustrial to the future climate state is found in the entire lower-to-middle stratosphere. In all model configurations the change in the lowermost stratosphere is mainly produced by resolved wave drag. However, the resolved wave drag contribution decreases with height, and at a certain pressure level the contribution of orographic gravity waves exceeds the resolved wave contribution. It turns out that the level, where this excess occurs, crucially depends on the vertical extent of the model. While in the high-top model the orographic gravity wave contribution exceeds the contribution of resolved waves already below $70 \mathrm{hPa}$, the level of the excess is shifted upward above the $70-\mathrm{hPa}$ level in the L31 model. This result may help explain the findings 
of Butchart et al. (2010), who analyzed many different CCMs with regard to the wave-type contribution to the 70-hPa upward mass flux and its trend. They found different origins of the derived mass flux trend among models with different configurations regarding vertical extent and resolution. If we consider now that the primary origin of the change in upward mass flux varies even in simulations performed with the same GCM with different vertical extents, one may conclude that the spread in the results obtained from the CCMs used in Butchart et al. (2010) are, at least partly, due to the different configurations of the CCMs.

While ECHAM6 as well as the vast majority of climate models simulate a BDC increase, observational age-of-air datasets (Engel et al. 2009) reveal an unchanged or even slightly decreasing BDC over the last decades. A separation of the total mean age of air into a contribution of transport along the residual circulation trajectories, and a contribution of mixing processes (Birner and Bönisch 2011), would allow us to further constrain the origin of the different trend derived from model and observational age-of-air datasets. Besides the different trend, there is also an offset between model and observational data. All ECHAM6 model configurations generally show a lower mean age of air than observed (Engel et al. 2009). As we identified reduced numerical diffusion through the tropopause already in the L95 model as the main origin of the older age of air compared to the L47 configuration, an even higher vertical model resolution might lead to a further reduction in the offset between model and observational data.

Acknowledgments. This study was funded by the German Research Foundation (DFG) through the project Stratospheric Change and its Role for Climate Prediction (SHARP). The authors thank Elisa Manzini, Ed Gerber, Alexey Karpechko, Hella Garny, and two anonymous reviewers for their comments on earlier drafts of this article.

\section{REFERENCES}

Andrews, D. G., J. R. Holton, and C. B. Leovy, 1987: Middle Atmosphere Dynamics. Academic Press, 481 pp.

Austin, J., and F. Li, 2006: On the relationship between the strength of the Brewer-Dobson circulation and the age of stratospheric air. Geophys. Res. Lett., 33, D17807, doi:10.1029/2006GL026867.

Birner, T., and H. Bönisch, 2011: Residual circulation trajectories and transit times into the extratropical lowermost stratosphere. Atmos. Chem. Phys., 11, 817-827, doi:10.5194/ acp-11-817-2011.

Butchart, N., and A. Scaife, 2001: Removal of chlorofluorocarbons by increased mass exchange between the stratosphere and troposphere in a changing climate. Nature, 410, 799-802.
_ J. Justin, J. R. Knight, A. A. Scaife, and M. L. Gallani, 2000: The response of the stratospheric climate to projected changes in the concentrations of well-mixed greenhouse gases from 1992 to 2051. J. Climate, 13, 2142-2159.

_ , and Coauthors, 2006: Simulations of anthropogenic change in the strength of the Brewer-Dobson circulation. Climate Dyn., 27, 727-741, doi:10.1007/s00382-006-0162-4.

_ , and Coauthors, 2010: Chemistry-climate model simulations of twenty-first century stratospheric climate and circulation changes. J. Climate, 23, 5349-5374.

_ , and Coauthors, 2011: Multimodel climate and variability of the stratosphere. J. Geophys. Res., 116, D05102, doi:10.1029/ 2010JD014995.

Eliassen, A., and E. Palm, 1960: On the transfer of energy in stationary mountain waves. Geofys. Publ., 12,1-23.

Engel, A., and Coauthors, 2009: Age of stratospheric air unchanged within uncertainties over the past 30 years. Nat. Geosci., 2, 28 31, doi:10.1038/ngeo388.

Garcia, R. R., and W. J. Randel, 2008: Acceleration of the BrewerDobson circulation due to increases in greenhouse gases. J. Atmos. Sci., 65, 2731-2739.

,$--\frac{1}{-}$ and D. E. Kinnison, 2011: On the determination of age of air trends from atmospheric trace species. J. Atmos. Sci., $\mathbf{6 8}$, $139-154$.

Garny, H., M. Dameris, W. Randel, G. E. Bodeker, and R. Deckert, 2011: Dynamically forced increase of tropical upwelling in the lower stratosphere. J. Atmos. Sci., 68, 1214-1233.

Giorgetta, M. A., E. Manzini, E. Roeckner, M. Esch, and L. Bengtsson, 2006: Climatology and forcing of the quasibiennial oscillation in the MAECHAM5 model. J. Climate, 19, 3882-3901.

Hall, T. M., and R. A. Plumb, 1994: Age as a diagnostic of stratospheric transport. J. Geophys. Res., 99 (D1), 1059-1070.

Haynes, P. H., M. E. McIntyre, T. G. Shepherd, C. J. Marks, and K. P. Shine, 1991: On the "downward control" of extratropical diabatic circulations by eddy-induced mean zonal forces. J. Atmos. Sci., 48, 651-680.

Hegglin, M. I., and T. G. Shepherd, 2009: Large climate-induced changes in ultraviolet index and stratosphere-to-troposphere ozone flux. Nat. Geosci., 2, 687-691, doi:10.1038/ngeo604.

Hines, C. O., 1997: Doppler-spread parameterization of gravitywave momentum deposition in the middle atmosphere. Part 1: Basic formulation. J. Atmos. Sol. Terr. Phys., 59, 371-386, doi:10.1016/S1364-6826(96)00079-X.

Jiang, X., S. J. Eichelberger, D. L. Hartmann, R. Shia, and Y. L. Yung, 2007: Influence of doubled $\mathrm{CO}_{2}$ on ozone via changes in the Brewer-Dobson circulation. J. Atmos. Sci., 64, 2751-2755.

Karpechko, A. Y., and E. Manzini, 2012: Stratospheric influence on tropospheric climate change in the Northern Hemisphere. J. Geophys. Res., 117, D05133, doi:10.1029/2011JD017036.

Li, F., J. Austin, and J. Wilson, 2008: The strength of the BrewerDobson circulation in a changing climate: Coupled chemistryclimate model simulations. J. Climate, 21, 40-57.

Lott, F., and M. J. Miller, 1997: A new subgrid-scale orographic drag parametrization: Its formulation and testing. Quart. J. Roy. Meteor. Soc., 123, 101-127, doi:10.1002/qj.49712353704.

Lu, J., G. Chen, and D. M. W. Frierson, 2008: Response of the zonal mean atmospheric circulation to El Niño versus global warming. J. Climate, 21, 5835-5851.

Manzini, E., and N. A. McFarlane, 1998: The effect of varying the source spectrum of a gravity wave parameterization in a middle atmosphere general circulation model. J. Geophys. Res., 103 (D24), 31 523-31 540. 
and J. Feichter, 1999: Simulation of the $\mathrm{SF}_{6}$ tracer with the middle atmosphere MAECHAM4 model: Aspects of the large-scale transport. J. Geophys. Res., 104 (D24), $31097-$ 31108.

_- M. A. Giorgetta, M. Esch, L. Kornblueh, and E. Roeckner, 2006: The influence of sea surface temperatures on the northern winter stratosphere: Ensemble simulations with the MAECHAM5 model. J. Climate, 19, 3863-3881.

Marsland, S., 2003: The Max-Planck-Institute global ocean/sea ice model with orthogonal curvilinear coordinates. Ocean Modell., 5, 91-127, doi:10.1016/S1463-5003(02)00015-X.

McLandress, C., and T. G. Shepherd, 2009: Simulated anthropogenic changes in the Brewer-Dobson circulation, including its extension to high latitudes. J. Climate, 22, 1516-1540.

Nakicenovic, N., and R. Swart, 2000: Special Report on Emissions Scenarios. Cambridge University Press, 598 pp.

Okamoto, K., K. Sato, and H. Akiyoshi, 2011: A study on the formation and trend of the Brewer-Dobson circulation. J. Geophys. Res., 116, D10117, doi:10.1029/2010JD014953.

Pawson, S., and Coauthors, 2000: The GCM-Reality Intercomparison Project for SPARC (GRIPS): Scientific issues and initial results. Bull. Amer. Meteor. Soc., 81, 781-796.

Plumb, R. A., and R. C. Bell, 1982: A model of the quasi-biennial oscillation on an equatorial beta-plane. Quart. J. Roy. Meteor. Soc., 108, 335-352, doi:10.1002/qj.49710845604.

—_ and J. Eluszkiewicz, 1999: The Brewer-Dobson circulation: Dynamics of the tropical upwelling. J. Atmos. Sci., 56, 868890.

Rind, D., R. Suozzo, N. K. Balachandran, and M. J. Prather, 1990: Climate change and the middle atmosphere. Part I: The doubled $\mathrm{CO}_{2}$ climate. J. Atmos. Sci., 47, 475-494.

, D. Shindell, P. Lonergan, and N. K. Balachandran, 1998: Climate change and the middle atmosphere. Part III: The doubled $\mathrm{CO}_{2}$ climate revisited. J. Climate, 11, 876-894.
Roeckner, E., and Coauthors, 2003: The atmospheric general circulation model ECHAM 5. Part I: Model description. Max Planck Institute for Meteorology Rep. 349, 140 pp. [Available online at http://www.mpimet.mpg.de/fileadmin/publikationen/ Reports/max_scirep_349.pdf.]

_ horizontal and vertical resolution in the ECHAM5 atmosphere model. J. Climate, 19, 3771-3791.

Schmidt, H., and Coauthors, 2013: The response of the middle atmosphere to anthropogenic and natural forcing in the CMIP5 simulations with the MPI-ESM. J. Adv. Model. Earth Syst., doi:10.1002/jame.20014, in press.

Semeniuk, K., and T. G. Shepherd, 2001: Mechanisms for tropical upwelling in the stratosphere. J. Atmos. Sci., 58, 3097-3115.

Seviour, W. J. M., N. Butchart, and S. C. Hardiman, 2012: The Brewer-Dobson circulation inferred from ERA-Interim. Quart. J. Roy. Meteor. Soc., 138, 878-888, doi:10.1002/qj.966.

Shaw, T. A., and T. G. Shepherd, 2007: Angular momentum conservation and gravity wave drag parameterization: Implications for climate models. J. Atmos. Sci., 64, 190-203.

Shepherd, T. G., and C. McLandress, 2011: A robust mechanism for strengthening of the Brewer-Dobson circulation in response to climate change: Critical-layer control of subtropical wave breaking. J. Atmos. Sci., 68, 784-797.

Sigmond, M., P. C. Siegmund, E. Manzini, and H. Kelder, 2004: A simulation of the separate climate effects of middle-atmospheric and tropospheric $\mathrm{CO}_{2}$ doubling. J. Climate, 17, 2352-2367.

Stevens, B., and Coauthors, 2013: The atmospheric component of the MPI-M earth system model: ECHAM6. J. Adv. Model. Earth Syst., doi:10.1002/jame.20015, in press.

van Vuuren, D. P., and Coauthors, 2011: The representative concentration pathways: An overview. Climatic Change, 109, 5-31.

Waugh, D., and T. Hall, 2002: Age of stratospheric air: Theory, observations, and models. Rev. Geophys., 40, 1010, doi:10.1029/ 2000RG000101. 


\title{
CORRIGENDUM
}

\author{
FELIX BUNZEL \\ Max Planck Institute for Meteorology, and International Max Planck Research School on Earth System Modelling, \\ Hamburg, Germany \\ HAUKE SCHMIDT \\ Max Planck Institute for Meteorology, Hamburg, Germany
}

There were two errors in the main body of Bunzel and Schmidt (2013). In section 1 in the first column on p. 1438, the expansion of the acronym SPARC was incorrect. The correct expansion should be Stratospheric Processes and Their Role in Climate (SPARC). Also, the sentence in section 4 spanning pages 1444-1445 was incorrectly edited. The sentence should read, "Regions of significantly younger air in the L31 model show up above the extratropical tropopause in both hemispheres, which may be the result of a faster BDC in the uppermost model levels or increased horizontal mixing in the L31 model compared to the L95 version."

The staff of the Journal of the Atmospheric Sciences regrets any inconvenience these errors may have caused.

\section{REFERENCE}

Bunzel, F., and H. Schmidt, 2013: The Brewer-Dobson circulation in a changing climate: Impact of the model configuration. J. Atmos. Sci., 70, 1437-1455.

Corresponding author address: Felix Bunzel, Max Planck Institute for Meteorology, Bundesstr. 53, 20146 Hamburg, Germany. E-mail: felix.bunzel@zmaw.de 